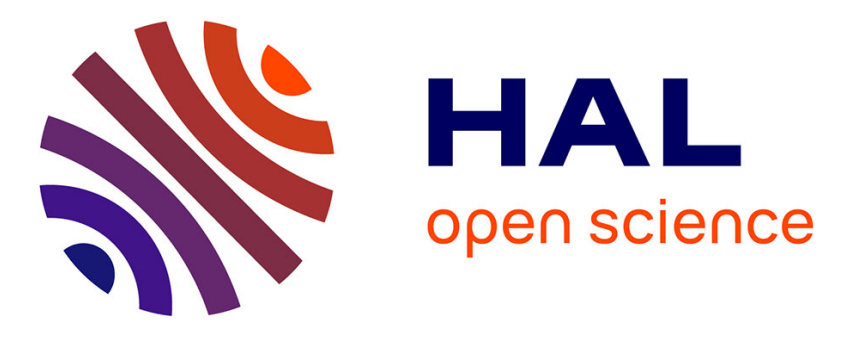

\title{
Mitotic block and delayed lethality in HeLa epithelial cells exposed to Escherichia coli BM2-1 producing cytotoxic necrotizing factor type 1
}

Jean de Rycke, Philippe Mazars, Jean-Philippe Nougayrede, Christian Tasca, Michèle Boury, Frédéric Herault, Annie Valette, Eric Oswald

\section{To cite this version:}

Jean de Rycke, Philippe Mazars, Jean-Philippe Nougayrede, Christian Tasca, Michèle Boury, et al.. Mitotic block and delayed lethality in HeLa epithelial cells exposed to Escherichia coli BM2-1 producing cytotoxic necrotizing factor type 1 . Infection and Immunity, 1996, 64 (5), pp.1694-1705. hal-02648871

\section{HAL Id: hal-02648871 \\ https://hal.inrae.fr/hal-02648871}

Submitted on 1 Jun 2020

HAL is a multi-disciplinary open access archive for the deposit and dissemination of scientific research documents, whether they are published or not. The documents may come from teaching and research institutions in France or abroad, or from public or private research centers.
L'archive ouverte pluridisciplinaire HAL, est destinée au dépôt et à la diffusion de documents scientifiques de niveau recherche, publiés ou non, émanant des établissements d'enseignement et de recherche français ou étrangers, des laboratoires publics ou privés. 


\section{Infection and Immunity}

Mitotic block and delayed lethality in HeLa epithelial cells exposed to Escherichia coli BM2-1 producing cytotoxic necrotizing factor type 1.

J De Rycke, P Mazars, J P Nougayrede, C Tasca, M Boury, F Herault, A Valette and E Oswald

Infect. Immun. 1996, 64(5):1694.

Updated information and services can be found at:

http://iai.asm.org/content/64/5/1694

\section{These include:}

CONTENT ALERTS

Receive: RSS Feeds, eTOCs, free email alerts (when new articles cite this article), more» 


\title{
Mitotic Block and Delayed Lethality in HeLa Epithelial Cells Exposed to Escherichia coli BM2-1 Producing Cytotoxic Necrotizing Factor Type 1
}

JEAN DE RYCKE,${ }^{1 *}$ PHILIPPE MAZARS, ${ }^{2}$ JEAN-PHILIPPE NOUGAYREDE,${ }^{1}$ CHRISTIAN TASCA, ${ }^{1}$ MICHÈLE BOURY, ${ }^{1}$ FRÉDÉRIC HERAULT, ${ }^{1}$ ANNIE VALETTE, ${ }^{2}$ AND ERIC OSWALD ${ }^{1}$

Laboratoire Associé de Microbiologie Moléculaire, Institut National de la Recherche Agronomique and Ecole Nationale Vétérinaire, ${ }^{1}$ and Laboratoire de Pharmacologie et Toxicologie Fondamentales, Centre National de la Recherche Scientifique, ${ }^{2}$ Toulouse, France

Received 25 September 1995/Returned for modification 2 February 1996/Accepted 1 March 1996

\begin{abstract}
The cytopathic effect (CPE) of Escherichia coli producing cytotoxic necrotizing factor type 1 (CNF1) was investigated by using a human epithelial cell (HeLa) model of infection with CNF1-producing $E$. coli BM2-1. This strain was shown to bind loosely, but massively, to HeLa cells. A 4-h interaction between bacteria and eukaryotic cells triggered the delayed appearance of a progressive dose-dependent $\mathrm{CPE}$ characterized by (i) intense swelling of cells accompanied by the formation of a dense network of actin stress fibers, (ii) inhibition of cell division due to a complete block in the $G_{2}$ phase of the cell cycle, and (iii) nucleus swelling and chromatin fragmentation. These alterations resulted in cell death starting about 5 days after interaction. The absence of multinucleation clearly distinguished the CPE from the effect produced by free CNF1, which was shown to result in a true endomitosis. Moreover, the CPE was neither produced by cell-free culture supernatants of infected cells nor prevented by a CNF1-neutralizing antiserum. Pathogenicity was completely abolished after Tn5::phoA insertion mutagenesis in the cnf-1 structural gene but not restored by trans complementation with a recombinant plasmid containing intact $c n f-1$ and its promoter. These results suggest that a gene downstream of $c n f-1$, essential to the induction of the CPE, was affected by the mutation. On the other hand, transformation of the wild-type strain BM2-1 with the same recombinant plasmid leads to a significant increase in both CNF1 activity and CPE, demonstrating the direct contribution of CNF1 to the CPE. In conclusion, the pathogenicity of $E$. coli BM2-1 for HeLa cells results from a complex interaction involving cnf-1 and associated genes and possibly requiring a preliminary step of binding of bacterial organisms to target cells.
\end{abstract}

Cytotoxic necrotizing factors (CNF) form a recently discovered category of Escherichia coli toxins that induce on various eukaryotic cells in culture a drastic reorganization of the microfilamental network into thick stress fibers. In cell culture assays, this phenomenon is accompanied by a block of cytokinesis, leading to the formation of giant multinucleated cells (6, $10,18,27,30)$. This original biological activity is associated with the ability of CNF to induce a posttranslational modification of the $21-\mathrm{kDa}$ rho GTP-binding protein, which is involved in the regulation of the microfilamental network (28). Two types of CNF, with apparent molecular masses of 110 to $115 \mathrm{kDa}(5,11,26)$, have been characterized. They can be distinguished on the basis of clinical origin, in vivo toxicity, and genetic determination (9). CNF1 is found in E. coli isolates from septicemia, diarrhea, and urinary tract infections of humans $(1,7)$ and animals $(4,10)$. It is chromosome encoded and moderately dermonecrotic $(6,15)$. CNF2 is produced only by some $E$. coli isolates from septicemic or diarrheic young ruminants $(4,10)$, is plasmid encoded $(27)$, and is highly dermonecrotic (9). In spite of these differences, the genes encoding CNF1 and CNF2 both comprise 3,045 nucleotides and have $85.7 \%$ identical residues and $99 \%$ conserved residues $(15,28)$.

Although significant knowledge of the biological and molecular properties of CNF toxins has accumulated over the years, there is as yet only indirect evidence to substantiate the role of

* Corresponding author. Mailing address: Laboratoire INRA Associé de Microbiologie Moléculaire, Ecole Nationale Vétérinaire, 23 Chemin des Capelles, 31076 Toulouse Cedex, France. Phone: (33) 61 1938 85. Fax: (33) 61193975. these toxins as true virulence factors. The available evidence is first based on their potent toxic properties, including necrotoxicity in the rabbit skin test and lethality for mice and for young ruminants after parenteral administration $(9,12)$. Another interesting property is the ability of CNF1 to induce phagocyte behavior in cultured epithelial cell lines (16). If relevant in vivo, the latter mechanism would allow the bacteria to be taken up by epithelial cells, a phenomenon that could account for the frequent association of CNF-producing $E$. coli with systemic infections in humans and animals. The second line of argument is provided by the ability of CNF-producing E. coli to produce septicemia in animals experimentally infected by the oral route, such as calves for CNF2 isolates (32) and pigs for CNF1 isolates (40). However, in the above-mentioned experiments, the exact contribution of $\mathrm{CNF}$ in virulence was not examined, for instance, through the comparison of parental strains with isogenic mutants with CNF specifically deleted.

A major obstacle to the comprehension of the role of $\mathrm{CNF}$ in the virulence of CNF-producing $E$. coli is the fact that, in vitro at least, the toxin remains associated with the bacteria and is not detectably released into the culture medium $(6,11)$. A prerequisite for CNF activity on target cells would therefore be its release through lysis of $E$. coli organisms on contact with the epithelium. Another possible strategy could be an intimate interaction between $E$. coli and eukaryotic cells, leading to specific translocation of the toxin through the host cell membrane, a mechanism that has been demonstrated for, for instance, Yersinia YopE cytotoxin (29).

In the present paper, we discuss an original cytopathic effect (CPE) induced in cultured HeLa cells following a temporary 
interaction with $E$. coli BM2-1, a prototype CNF1-producing isolate from a calf with enteritis (10). The scope of this study was firstly to characterize this CPE by using several complementary and specific biological criteria and secondly to assess, on a molecular basis, the possible contribution of established virulence factors in the CPE, with the main emphasis on CNF1. We show that the interaction induces a profound reorganization of the HeLa cell cytoskeleton and a mitosis block in the $\mathrm{G}_{2}$ phase of the cell cycle, resulting in specific nuclear alterations and delayed cytolethality. We also provide evidence that although the CPE is related to the presence of the CNF1 structural gene, it is clearly distinguishable from the effect induced by free CNF1.

\section{MATERIALS AND METHODS}

E. coli strains and plasmids. E. coli BM2-1 (serotype O2:K53,91:H1) was the prototype CNF1-producing isolate used throughout this study. This strain has been described in previous reports $(10,11)$. It originated from the fecal content of a diarrheic calf and produces alpha-hemolysin. This strain has been kindly tested for the presence of other known E. coli virulence genes by J. Mainil (Faculty of Veterinary Medicine, University of Liège, Liège, Belgium) and by $\mathrm{C}$. Le Bouguenec (Pasteur Institute, Paris, France). Genes encoding various fimbriae (PapA, PapG, K88, K99, 987P, type 1, S, and F1C), nonfimbrial adhesin (Afa), the attaching-effacing phenotype (Bfpa and Eae), and verotoxins were tested for. The strain was found to be positive for type 1 and S and F1C fimbriae, respectively. The presence of $\mathrm{F} 1 \mathrm{C}$ fimbriae was confirmed by seroagglutination with a specific F1C antiserum (kindly provided by M. Dho-Moulin, Institut National de la Recherche Agronomique, Nouzilly, France). This antiserum was produced against purified F1C fimbriae from an E. coli HB101 laboratory strain containing reference plasmid pPIL110-51 (37). The presence of F1C fimbriae in strain BM2-1 was confirmed by the absence of mannose-resistant agglutination of bovine erythrocytes, as previously described (37).

Laboratory strains $E$. coli HB101 (hsdR hsdM recA supE44 lacZ4 leuB6 proA2 thi-1 $\mathrm{Sm}^{\mathrm{r}}$ ) and E. coli SM10ג pir (thi-1 thr-1 leuB6 tonA21 lacY1 supE44 rec $A:: \mathrm{RP} 4-2-\mathrm{Tc}:: \mathrm{Mu} \mathrm{Km^{ \textrm {r } }}$ ) were used as specified in transformation and plasmid mobilization experiments.

Plasmid pISS392 contains cnf- 1 in a $3.5-\mathrm{kb}$ insert isolated from the genomic DNA of E. coli EB35 (15). This plasmid was kindly provided by V. Falbo (Istituto Superiore di Sanitá, Rome, Italy). The broad-host-range pRT733 vector was used to deliver the TnphoA transposon (35). This suicide plasmid cannot replicate without the $\pi$ protein encoded by the $\lambda$ pir transducing phage. The pILL570-Not I vector $\left(\mathrm{Sp}^{\mathrm{r}}, 5.3 \mathrm{~kb}\right)$ is a derivative of pILL570 with an extra NotI site and EcoRI site in the polylinker (22). The pRT733 and pILL570-NotI vectors can be mobilized by RP4-containing donor strains.

Isolation and molecular analysis of a mutant with a Tn5::phoA insertion mutation in the CNF1 structural gene. Random insertions of TnphoA into the BM2-1 chromosome were accomplished through the use of donor strain SM10 $\lambda$ pir carrying the suicide plasmid pRT733 (35). After mating of donor strain SM10 $\lambda$ pir(pRT733) with recipient strain BM2-1, transconjugants were selected on M9 minimal agar supplemented with $1 \mu \mathrm{g}$ of thiamine per $\mathrm{ml}$ and $25 \mu \mathrm{g}$ of kanamycin per ml (35). Resulting colonies were tested for the production of CNF1 in a simplified assay of cytotoxicity for HeLa cells, using frozen-thawed bacterial extracts, as previously described (34). Six of about 4,000 selected clones lacked detectable CNF1 activity in cell extracts, while retaining hemolytic activity. As shown by the subsequent molecular analysis, among those six clones, only one, namely G2-8, fulfilled the following two criteria: (i) lack of cointegration of the entire plasmid and (ii) occurrence of a single insertion in the CNF1 structural gene. The lack of the specific $115-\mathrm{kDa}$ CNF1 protein was confirmed by Western blot (immunoblot) analysis, as previously described (11).

Genomic DNA preparations of CNF1-defective mutants were analyzed by Southern blotting. DNA probes were produced by PCR amplification. A 693-bp internal DNA fragment of cnf-1 was amplified with primers CNF-U781 (5'TTATATAGTCGTCAAGATGGA-3') and CNF-L1473 (5'-TTCATAGTAGA TGCCGCTCAG-3') (25). A 767-bp internal DNA fragment of TnphoA was amplified with primers: TnPhoA-U4031 (5'-CAACCTGCCATCACGAGATTT $\left.-3^{\prime}\right)$ and TnPhoA-L5045 (5'-GAAAAGCGGCTGGAACCATTC-3'). One additional TnphoA primer, namely TnPhoA-L54 (5'-AGCAGCCCGGTTTTCCAG AAC-3'), and three additional $c n f-1$ primers (25), namely CNF1-L3044 (5'-GG CCAATAAATAATTTCCCGAATC-3'), CNF1-U1843 (5'-GGGGGAAGTAC AGAAGAATTA-3'), and CNF1-L2934 (5'-TTGCCGTCCACTCTCACCAG $\left.\mathrm{T}-3^{\prime}\right)$, were used to directly localize by PCR the TnphoA insertion in the cnf-1 gene.

Recombinant DNA techniques were performed according to standard procedures (31). PCR amplification of DNA fragments was carried out by using a commercial kit (GenAmp; Perkin-Elmer Cetus) according to the instructions of the manufacturer. Nonradioactive labelling and detection of nucleic acids were carried out by using a commercial kit (DIG-high prime; Boehringer Mannheim). The DNA probes were labelled with digoxigenin (DIG)-dUTP via random- primed labelling. DIG-labelled hybrids were detected with an anti-DIG-alkaline phosphatase conjugate and visualized with the chemiluminescence substrate CDP-Star.

Assay of interaction between HeLa cells and bacterial cultures. HeLa cells (ATCC CCL2.2) were grown to confluence, at $37^{\circ} \mathrm{C}$ and in a $5 \% \mathrm{CO}_{2}$ atmosphere, in Eagle minimum essential medium (MEM) with Earle salts and Lglutamine (catalog no. 61100; Gibco) supplemented with $10 \%$ fetal calf serum (FCS). Twenty-four hours before the test of interaction, cells were trypsinized and seeded in 24-well tissue culture plates (catalog no. 3047; Falcon) so as to give $2.5 \cdot 10^{4}$ cells per well in a $500-\mu \mathrm{l}$ volume of MEM. Also, $24 \mathrm{~h}$ before the test, $E$. coli strains were precultivated in MEM without $\mathrm{FCS}$ at $37^{\circ} \mathrm{C}$ and in a $5 \% \mathrm{CO}_{2}$ atmosphere by seeding Luria broth (LB) glycerol storage culture at a ratio of $1 / 100$. At the time of testing, cell monolayers in a 24 -well plate were washed twice with prewarmed Earle balanced saline solution (EBSS) and medium was replaced by $470 \mu \mathrm{l}$ of Eagle MEM with Earle salts and $25 \mathrm{mM} \operatorname{HEPES}(\mathrm{N}-2$ hydroxyethylpiperazine- $N^{\prime}$-2-ethanesulfonic acid) (catalog no. 32360; Gibco) supplemented with $5 \%$ FCS complemented with anti-alpha-hemolysin antibodies, in order to prevent the rapid cytolytic activity caused by E. coli alphahemolysin (8). Antibody preparation is described below. Bacterial cultures were centrifuged $(5000 \times g, 20 \mathrm{~min})$, and the pellet was suspended in MEM so as to constitute the required inoculum. Cell cultures were then seeded with $30 \mu \mathrm{l}$ of bacterial suspensions, and plates were incubated at $37^{\circ} \mathrm{C}$ in a $5 \% \mathrm{CO}_{2}$ atmosphere. After $4 \mathrm{~h}$ of interaction, wells were washed four times with EBSS and medium was replaced by Eagle MEM with Earle salts and L-glutamine supplemented with $10 \%$ FCS and $200 \mu \mathrm{g}$ of gentamicin per ml. Plates were then incubated at $37^{\circ} \mathrm{C}$ in a $5 \% \mathrm{CO}_{2}$ atmosphere for specified periods of time (from 1 to 7 days), medium being renewed every other day. Cellular alterations resulting from interaction with bacteria were demonstrated and quantified after methylene blue staining as described below.

In other instances, mentioned below, assays of interaction were carried out in tissue culture Petri dishes (100 by $20 \mathrm{~mm}$; catalog no. 3003; Falcon) seeded with $8 \cdot 10^{5}$ cells, in a 16 -ml volume of medium, or in 8 -well Lab-Tek chamber slides (Nunc) seeded with $1.5 \cdot 10^{4}$ cells per well, in a volume of $300 \mu \mathrm{l}$.

Demonstration of loose adhesion. Tests of interaction were performed in 8-well Lab-Tek chamber slides for $4 \mathrm{~h}$. At the end of the assay, $200 \mu \mathrm{l}$ of a $2.5 \%$ solution of glutaraldehyde in EBSS was added to the culture medium (final glutaraldehyde concentration, $1 \%$ ). Slides were then incubated at $4^{\circ} \mathrm{C}$ for $1 \mathrm{~h}$. At the end of the fixation period, wells were removed and slides were immersed in a vertical position for $10 \mathrm{~min}$ in a glass container filled with EBSS. This washing procedure almost completely eliminated nonspecific binding to glass. Slides were dried at $37^{\circ} \mathrm{C}$ for $15 \mathrm{~min}$ and stained for $30 \mathrm{~min}$ in a $1 / 10$ dilution of Giemsa in neutral water. Slides were then observed by microscopy with a $40 \times$ objective lens.

Detection of cytotoxic activity in culture supernatants and bacterial lysates. Assays of interaction were carried out under the conditions described above, with tissue culture plates $(100$ by $20 \mathrm{~mm})$. After $4 \mathrm{~h}$ of interaction, bacterial cultures $(16 \mathrm{ml})$ were removed from assay plates and centrifuged $(5,000 \times \mathrm{g}, 30 \mathrm{~min})$ at $4^{\circ} \mathrm{C}$. Supernatants were filtered (filter pore size, $0.2 \mu \mathrm{m}$ ) and placed immediately onto fresh HeLa cell monolayers in similar tissue culture plates. After 4 or $8 \mathrm{~h}$ of incubation, culture supernatants were replaced by regular cell culture medium and the occurrence of cytotoxic effects was monitored up to day 7 . Bacterial lysates were prepared by sonication of bacterial pellets obtained from centrifugation of 4-h interaction cultures $(16 \mathrm{ml})$, as described above. Bacterial pellets were resuspended in a 5-ml volume of cold MEM containing HEPES (suspended) and FCS $(5 \%)$ and lysed by sonication at $4{ }^{\circ} \mathrm{C}(\mathrm{W} 225$ sonicator; Ultrasonics Inc.). After clarification by centrifugation $(5,000 \times g, 30 \mathrm{~min})$, lysates were filtered (filter pore size, $0.2 \mu \mathrm{m})$, reconstituted in their initial volume $(16 \mathrm{ml})$ of complete culture medium, and placed onto fresh HeLa cell monolayers. After 4 or $8 \mathrm{~h}$ of incubation, culture supernatants were replaced by regular cell culture medium and the occurrence of cytotoxic effects was monitored up to day 7 .

Demonstration of morphological and cytoskeletal changes. Tests of interaction were performed in 8-well Lab-Tek chamber slides as described above. At specified times, morphological and cytoskeletal changes were demonstrated by means of an immunoperoxidase technique that allows simultaneous visualization of both cytoskeleton and nuclei. Cell monolayers were washed once with cytoskeleton buffer (CB) consisting of EBSS without calcium and magnesium (catalog no. 041-04150; Gibco) containing 5 mM PIPES [piperazine- $N, N^{\prime}$-bis $(2$ ethanesulfonic acid)] (Aldrich), $2 \mathrm{mM} \mathrm{MgCl}$, and $2 \mathrm{mM}$ EGTA [ethylene glycol-bis( $\beta$-aminoethyl ether)- $N, N, N^{\prime}, N^{\prime}$-tetraacetic acid] (Sigma). They were then simultaneously fixed and permeabilized with $\mathrm{CB}$ supplemented with $0.1 \%$ glutaraldehyde, $0.75 \%$ Triton X-100, and $5 \mathrm{mM}$ phallacidin (Sigma), applied over a 2-min period. After one washing with $\mathrm{CB}$, fixation was consolidated by adding $\mathrm{CB}$ containing $1 \%$ glutaraldehyde and incubating the mixture for $15 \mathrm{~min}$. After three washings with phosphate-buffered saline (PBS) containing $1 \mathrm{mg}$ of bovine serum albumin (BSA) (Sigma) per $\mathrm{ml}$ (wt/vol), endogenous peroxidase activity was eliminated by application of $3 \%$ hydrogen peroxide for $5 \mathrm{~min}$. After three additional washings with PBS-BSA, slides were incubated for $2 \mathrm{~h}$ at room temperature at a 1/100 dilution in PBS-BSA of rabbit antiactin antibody (catalog no. A-2066; Sigma). After five washings in PBS, cytoskeleton structures were revealed by using an anti-rabbit Extravidin peroxidase kit (Sigma) according to the instructions of the manufacturer. Briefly, this staining procedure includes three steps: (i) application of biotinylated goat anti-rabbit antibody, (ii) reaction 
with a streptavidin-peroxidase compound, and (iii) development with peroxidase substrate 3,3'-diamino-benzidine. Slides were then counterstained with Mayer's hemalum (RAL, Paris, France) for $5 \mathrm{~min}$, rinsed for $5 \mathrm{~min}$ in tap water, mounted in Entellan mounting medium (Merck), and observed by transmission microscopy.

Simple staining of F-actin with fluorescein phalloidin (Molecular Probes) was also performed, to detect in particular the possible formation of actin accretion on cell surfaces at the end of the interaction assay (21).

Measurement of invasion during assay of interaction. The occurrence of bacterial invasion during the interaction period was tested for according to the principles of a standard gentamicin assay, as previously described (14). The assay of interaction was performed in 6-well cell culture plates, by using three replicates per experimental point. Following a 4-h assay of interaction as described above, cell monolayers were washed five times with EBSS and cell culture medium containing $200 \mu \mathrm{g}$ of gentamicin per $\mathrm{ml}$ was added to the plates. After 3 and after $24 \mathrm{~h}$, cells were washed twice with EBSS to remove gentamicin and lysed with $0.1 \%$ Triton X-100 in EBSS. The number of viable bacterial organisms in cell lysates was determined after plating on Trypticase soya agar (TSA) plates.

Production of neutralizing antibodies against $E$. coli alpha-hemolysin. Alphahemolysin was produced from the $E$. coli laboratory strain $\mathrm{DH} 5 \alpha \mathrm{F}^{\prime}$ containing alpha-hemolysin recombinant plasmid pSF4000 (38). It was purified by polyethylene glycol precipitation of 3-h culture supernatants in Todd-Hewitt broth, and hemolytic activity on rabbit erythrocytes was measured according to the procedure previously described by Bhakdi et al. (3). Anti-alpha-hemolysin antibodies were produced in rabbits after repeated intramuscular injection of the purified toxin, by using Aluminject (Pierce) as the adjuvant. They were purified and concentrated by $40 \%$ ammonium sulfate precipitation, dialyzed against PBS (pH 7.4 ), and stored frozen at $-20^{\circ} \mathrm{C}$. Specificity of the antiserum for the $110-\mathrm{kDa}$ alpha-hemolysin was assessed by immunoblotting (data not shown). Neutralization of rabbit antiserum was titrated in the hemolysis assay described above and then in the assay of interaction on HeLa cells according to the antiserum's ability to prevent immediate cytolytic activity of E. coli BM2-1. The serum batch was used at a 1/50 final dilution in the assay of interaction.

Quantitation of cytotoxicity and cell viability. Assays of interaction were performed in 24-well tissue culture plates, and total protein content was determined at specified periods of time by means of a colorimetric assay using methylene blue, as described previously (39). Four wells were used for each experimental point. Briefly, after culture cells were fixed with $1 \%$ formaldehyde in PBS (pH 7.4) and then stained with a $1 \%(\mathrm{wt} / \mathrm{vol})$ solution of methylene blue in borate buffer for $10 \mathrm{~min}$. After five washes in borate buffer, stain was extracted with $0.1 \mathrm{M} \mathrm{HCl}$ and the optical density of the stain solution was read at $660 \mathrm{~nm}$ in a microplate reader (Dynatech)

For the counting of viable cells, assays of interaction were carried out in tissue culture Petri dishes $(100$ by $20 \mathrm{~mm}$ ). At specified times, cells were trypsinized and suspended in PBS and viable cell number was determined in a Thoma hemacytometer in the presence of $0.1 \%$ Trypan Blue.

Demonstration of specific nuclear alterations and DNA degradation. Tests of interaction were performed in 8-well Lab-Tek chamber slides as described above. For simple fluorescence staining of nuclei, cell monolayers were washed once with EBSS, fixed for $15 \mathrm{~min}$ in $1 \%$ formaldehyde in PBS, washed three times with PBS, permeabilized with $0.1 \%$ Triton X-100 in PBS, washed three times in PBS, and incubated for $10 \mathrm{~min}$ in a solution of $5 \mu \mathrm{g}$ of 4',6-diamidino-2-phenylindole (DAPI) per $\mathrm{ml}$ in PBS. After one additional washing in PBS, slides were mounted in SlowFade mounting medium (BioProbe) and observed by fluorescence microscopy.

The occurrence of 3'-hydroxyl ends of DNA fragments was detected in situ by the terminal deoxynucleotidyltransferase (TdT)-mediated dUTP nick-end-labelling technique (TUNEL), according to the method previously described by Gorczyca et al. (19). Briefly, preparations were fixed with $1 \%$ formaldehyde in PBS, washed as described above, permeabilized in pure acetone at $-20^{\circ} \mathrm{C}$ for $6 \mathrm{~min}$, and dried at room temperature to eliminate acetone. Monolayers were then incubated for $1 \mathrm{~h}$ in a reaction buffer $(\mathrm{pH}$ 6.6) containing $0.2 \mathrm{M}$ potassium cacodylate, $25 \mathrm{mM}$ Tris- $\mathrm{HCl}, 0.25 \mathrm{mg}$ of BSA per $\mathrm{ml}, 2.5 \mathrm{mM} \mathrm{CoCl}, 0.3 \mathrm{U}$ of TdT (catalog no. 220582; Boehringer) per $\mu \mathrm{l}$, and $1 \mathrm{nmol}$ of biotinylated dUTP (catalog no. B3029; Sigma) per $\mu$ l. After a 5-min washing in PBS, preparations were incubated for $30 \mathrm{~min}$ in the dark in $40 \mu \mathrm{g}$ of streptavidin fluorescein (catalog no. 1055097; Boehringer) per ml prepared in a buffer containing $4 \times$ concentrated saline-sodium citrate buffer, $0.1 \%$ Triton X-100, and 5\% (wt/vol) dry milk. Preparations were then washed three times in PBS, stained with a $5-\mu \mathrm{g} / \mathrm{ml}$ solution of DAPI in PBS, washed once, and mounted in SlowFade for observation by fluorescence microscopy.

Flow cytometry analysis. After trypsinization and washing in PBS, cells were fixed in $3.7 \%$ formaldehyde in PBS (pH 7.4) for 15 min on ice. Next, after three washes in PBS, cells were suspended in $70 \%$ ice-cold ethanol and immediately transferred to $-20^{\circ} \mathrm{C}$ for at least $2 \mathrm{~h}$. After fixation and permeabilization, $10^{6}$ cells were rehydrated in PBS at room temperature and then incubated in the dark at $37^{\circ} \mathrm{C}$ for $30 \mathrm{~min}$ in $1 \mathrm{ml}$ of a PBS solution containing RNase $(1 \mathrm{mg} / \mathrm{ml})$ and propidium iodide $(10 \mu \mathrm{g} / \mathrm{ml})$. Flow cytometry analysis of the DNA content was performed with a FACScan flow cytometer (Becton Dickinson). The data from $10^{4}$ cells were collected and analyzed by using LYSYS II software. The signals of orange fluorescence (propidium iodide) were measured by linear or logarithmic amplification.

\section{RESULTS}

CPE induced in HeLa cell cultures following interaction with $\boldsymbol{E}$. coli BM2-1. Nonconfluent HeLa cell cultures were infected for $4 \mathrm{~h}$ on day 1 with $E$. coli BM2-1, by using an initial bacterial concentration of about $10^{8} \mathrm{CFU} / \mathrm{ml}$ of cell culture medium, as described in Materials and Methods. As a control strain, we used $E$. coli $\mathrm{G} 2-8$, a hemolysin-positive CNF1-defective mutant of BM2-1 obtained through Tn5::pho $A$ insertion mutagenesis. As fully documented below, CNF1 deficiency in strain G2-8 resulted from a single transposon insertion in chf-1, the structural gene for CNF1. Anti-alpha-hemolysin antibodies were systematically added to the culture medium to prevent the immediate cytolytic effect of alpha-hemolysin produced by both the parental and mutant strains. After $4 \mathrm{~h}$ of infection, strains BM2-1 and G2-8 bound massively and specifically to cells but could be almost completely removed by repeated washing of cell monolayers (data not shown). After the washing, MEM was replaced by the same medium containing $10 \%$ FCS and $200 \mu \mathrm{g}$ of gentamicin per $\mathrm{ml}$ and cell cultures were further incubated for 1 to 7 days. Cells displayed no detectable morphological alterations at the end of the interaction period (day 1), but starting $24 \mathrm{~h}$ later (day 2) cells infected with strain BM2-1 developed a progressive CPE whose time course from day 1 to day 7 is depicted in Fig. 1. Morphologically, CPE was characterized by (i) progressive, marked swelling of cells and of their nuclei, (ii) formation of a dense network of actin stress fibers, (iii) lack of cell proliferation up to day 5, and (iv) partial destruction of cells from day 5, associated with nuclear fragmentation. In contrast, cells infected with strain G2-8 displayed no detectable alterations during the observation period and seemed to behave like noninfected control cells (data not shown), producing dense confluent monolayers on day 7 . The mean length of adherent altered cells at day 5 was more than 10 times that of normal cells. Mean diameter of nuclei was estimated to be approximately 2.5 -fold that of normal cells on the same day.

CPE induced by bacterial interaction was compared with the effect produced by sterile lysates of these interaction cultures. Sonicated extracts of $E$. coli BM2-1 interaction cultures, prepared in cell culture medium as described in Materials and Methods, were applied to new HeLa cell monolayers for $4 \mathrm{~h}$, after which regular cell culture medium was added. After at least $48 \mathrm{~h}$ of incubation, they induced the typical effects previously described for CNF1, i.e., cell enlargement, formation of actin stress fibers, and multinucleation (Fig. 2). Therefore, in comparison with the effect of free CNF1, the effect produced by bacterial interaction was characterized by the absence of multinucleation.

Simple staining with fluorescent phallacidin was also used at the end of the interaction period to check the possible accumulation of F-actin on the cell surface, as was observed with attaching-effacing $E$. coli (21). In our model, no local accumulation of F-actin was detectable.

We also examined whether CPE could be associated with some degree of bacterial invasion during the assay of interaction. Firstly, organisms associated with cells could be almost totally removed after repeated washes at the end of the interaction period, as observed after Giemsa staining of cell monolayers (data not shown). Secondly, after a 3- or a 24-h exposure of the infected monolayers to gentamicin, no viable colonies could be detected in their lysates.

Dose-response effect on cell proliferation and viability. The time course of cell death was first assessed by enumeration of viable cells following a 4-h interaction with an inoculum of $10^{8}$ cells per ml of culture medium (Fig. 3A). Cell number re- 
Parental CNF1-producing strain BM2-1

$\downarrow$

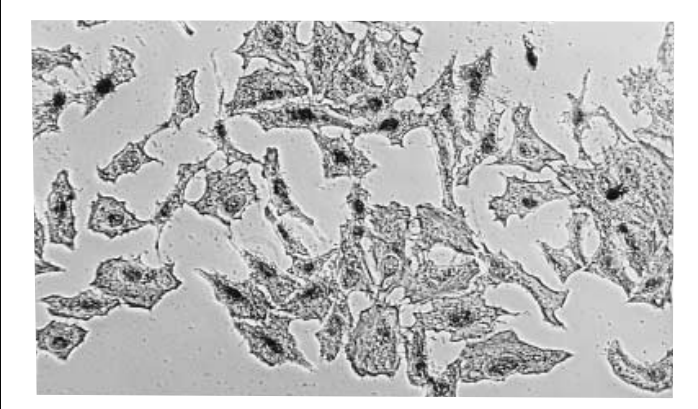

CNF1-deleted TnPhoA mutant G2-8

$\downarrow$

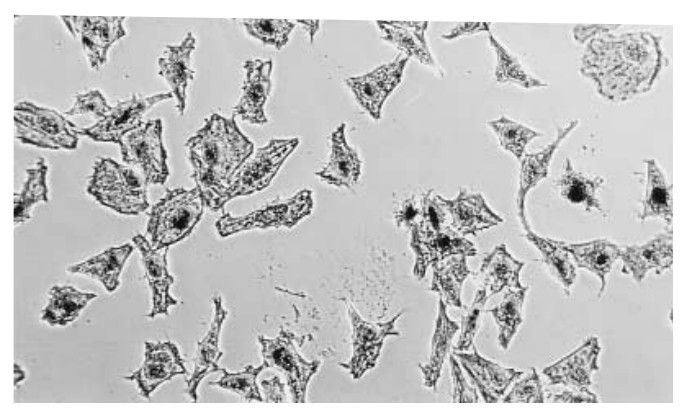

\section{DAY 3}
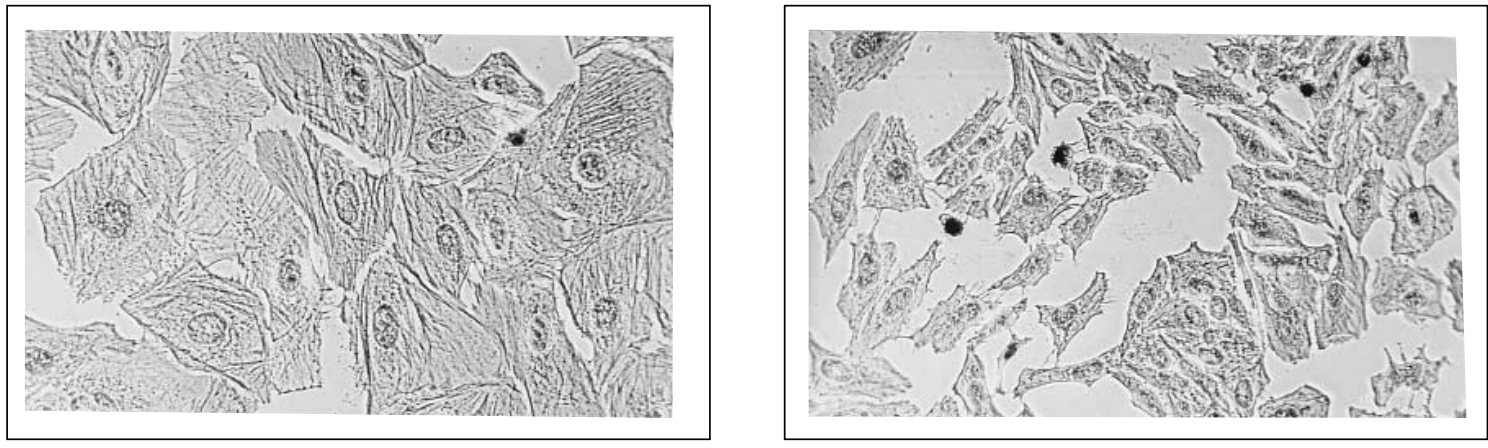

\section{DAY 5}
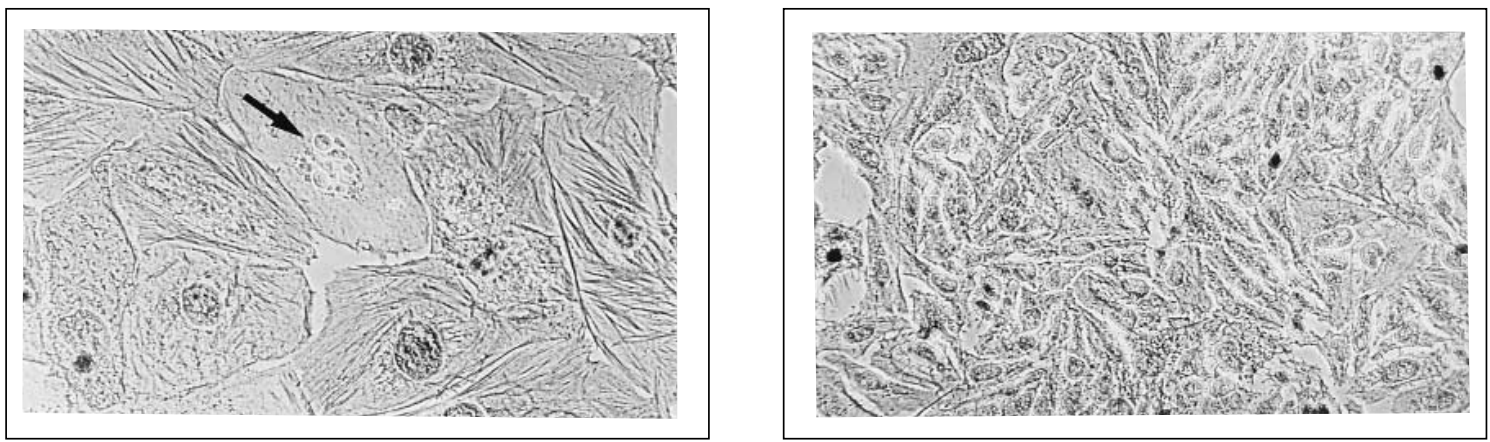

\section{DAY 7}
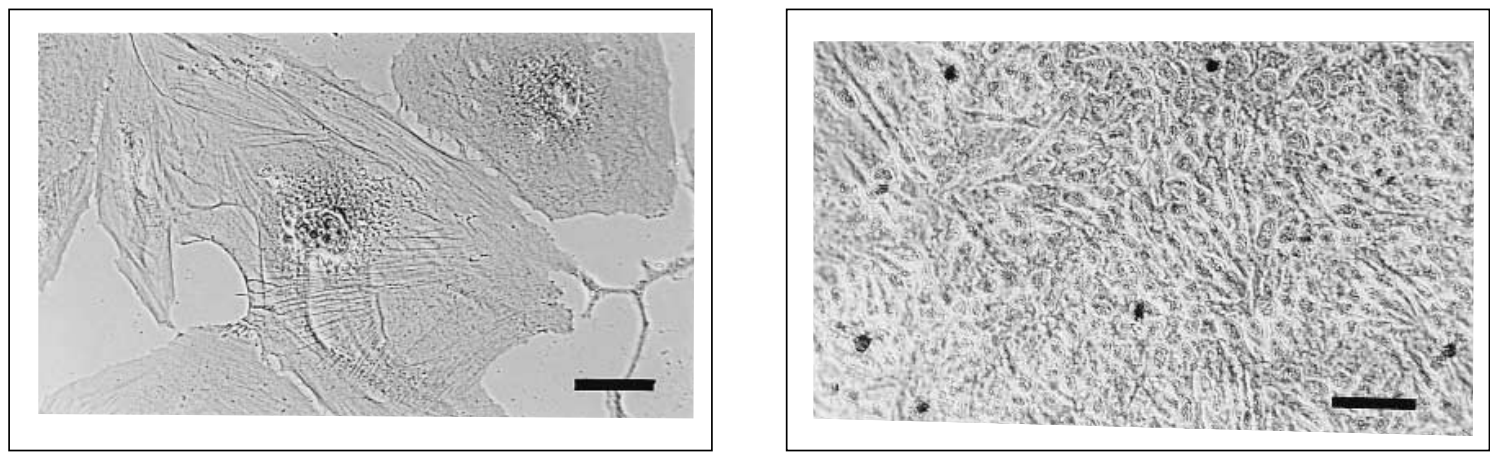

FIG. 1. Time course of morphological and cytoskeletal alterations induced in HeLa cell monolayers after interaction with CNF-producing E. coli BM2-1 (left column) or TnphoA mutant strain G2-8 lacking CNF1 production (right column). On day 1, HeLa cell cultures were infected for 4 h with bacterial cultures in the presence of anti-alpha-hemolysin neutralizing antibodies and then they were washed thoroughly to eliminate bacteria and incubated in cell culture medium containing gentamicin, as described in Materials and Methods. On day 1 (immediately after washing) and on days 3, 5, and 7, cells were fixed and actin filaments were stained by an immunoperoxidase method using antiactin rabbit antibodies, with counterstaining of nuclei with Mayer's hematoxylin. The same Zeiss $16 \times$ phase-contrast objective lens was used throughout. Bars $=20 \mu \mathrm{m}$. HeLa cells exposed to the parental strain, BM2-1, did not multiply and displayed progressive enlargement, strong development of actin stress fibers, and fragmentation of the nucleus (arrow). By contrast, cells exposed to mutant strain G2-8 displayed no detectable alterations and grew to confluence. 

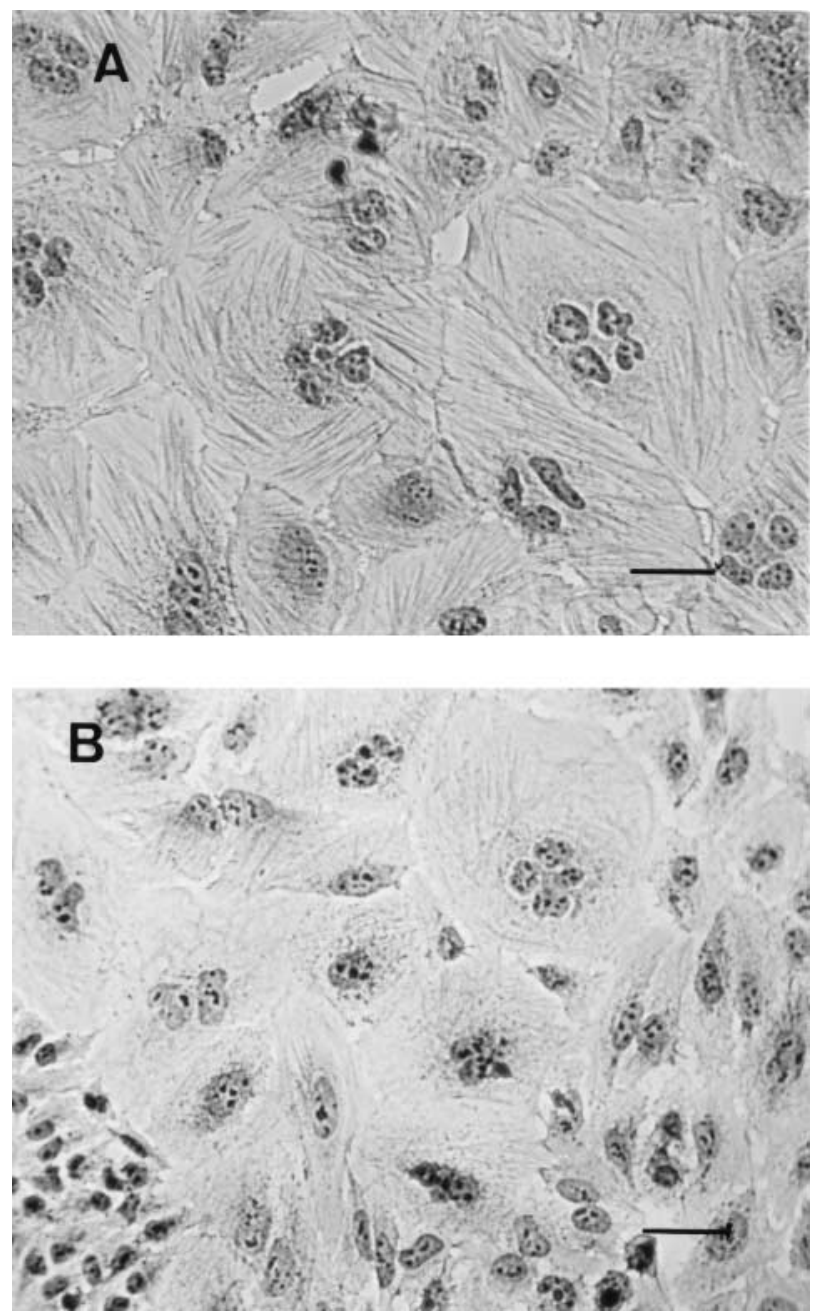

FIG. 2. CPE induced in HeLa cell monolayers by sterile lysates of BM2-1 cultures. Sterile sonicated extracts from 4-h interaction cultures were prepared as described in Materials and Methods and applied on day 1 to HeLa cell monolayers for $4 \mathrm{~h}$, after which they were replaced by regular cell culture medium. The CPE observed at day 3 (A) and day 5 (B) is shown. Staining was done by an immunoperoxidase technique with antiactin antibody, and counterstaining was done with Mayer's hematoxylin. A Zeiss $16 \times$ phase-contrast objective lens was used throughout. Bars $=20 \mu \mathrm{m}$.

mained approximately constant up to day 5 , at which time cell lethality started. A dose-response study, using total protein determination as measured by methylene blue staining, was carried out (Fig. 3B). Inhibition of cell proliferation was dose related, with total arrest observed with a starting inoculum of about $4 \cdot 10^{7} \mathrm{CFU} / \mathrm{ml}$ of medium. With smaller inocula, the cytotoxic effect was partial. Doses of bacteria that induced a total block in cell proliferation did not appear to completely inhibit protein synthesis, at least up to day 5. This observation should be considered in correlation with the spectacular increase in cell size that occurs during the same period. In this dose-response study, cell morphology was also systematically examined by inverted microscopy after methylene blue staining. With both lethal and sublethal inocula of strain BM2-1, altered cells displayed the same morphological alterations as described above and cell multinucleation was not significant. By comparison, control strain G2-8 produced no detectable effect, at least up to a starting inoculum of $2.4 \cdot 10^{8} \mathrm{CFU} / \mathrm{ml}$. The major consequence of bacterial interaction on cells was therefore a stopping of their proliferation, while the progressive and profound alterations inflicted on cells resulted in delayed cell death, starting from day 5 .

Chromatin alterations and in situ detection of DNA strand breaks by TdT assay. By using simple DNA staining with DAPI, three frequent and distinct morphological alterations, starting from day 5, were observed in cells exposed to strain BM2-1 (Fig. 4B): (i) complete disintegration of nuclei; (ii)
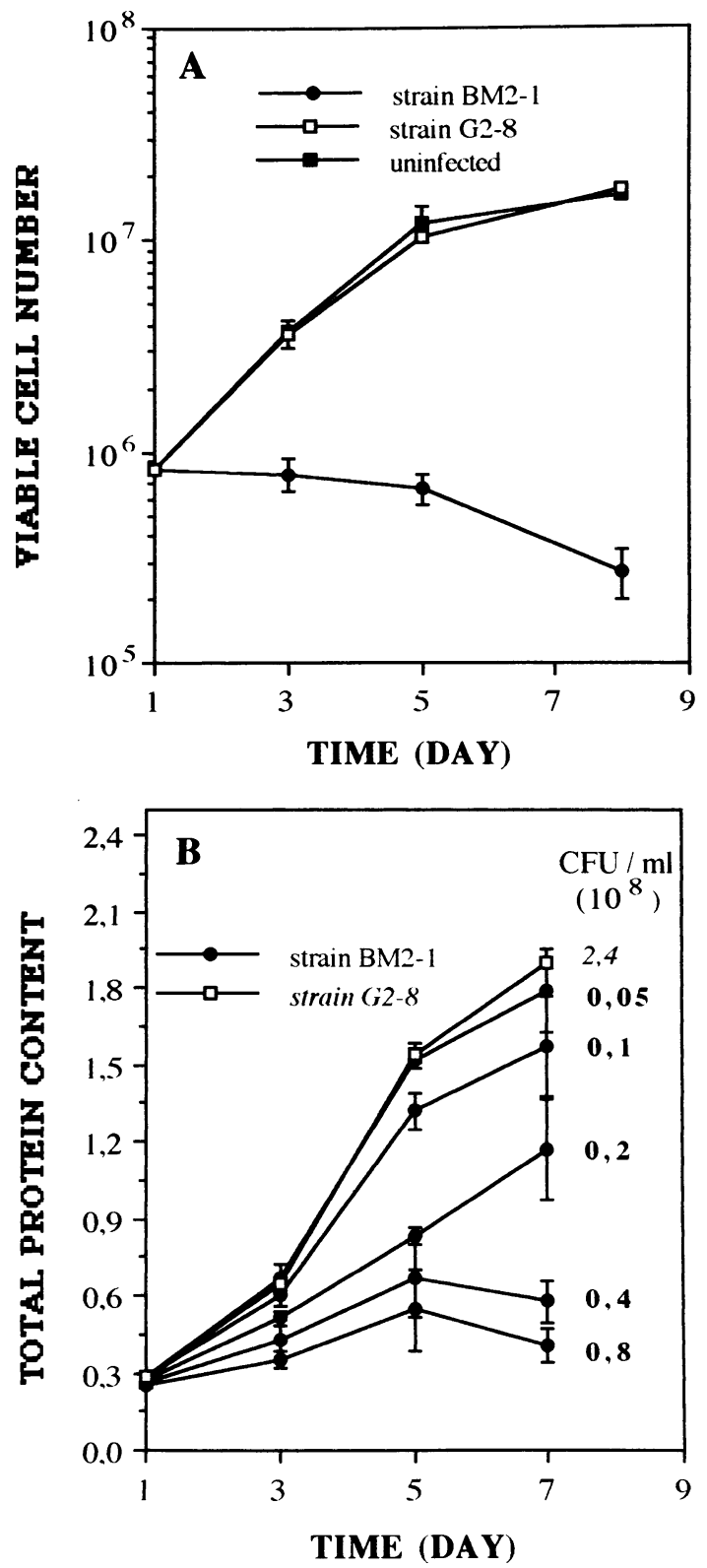

FIG. 3. Effect of bacterial interaction on cell proliferation and viability. On day 1, established HeLa cell cultures were infected for $4 \mathrm{~h}$ with bacterial cultures, and then they were washed thoroughly to eliminate bacteria and incubated in cell culture medium containing gentamicin for specified periods of time, as described in Materials and Methods. (A) Time course of change in HeLa cell viable counts after interaction with CNF1-producing $E$. coli BM2-1 in comparison with mutant strain G2-8 lacking CNF1 (three plates per experimental point; error bars indicate standard errors). (B) Dose-dependent cytotoxicity exerted by E. coli BM2-1 as assessed by determination of total protein content of cell monolayers by using methylene blue staining (four wells per experimental point; error bars indicate standard errors). 

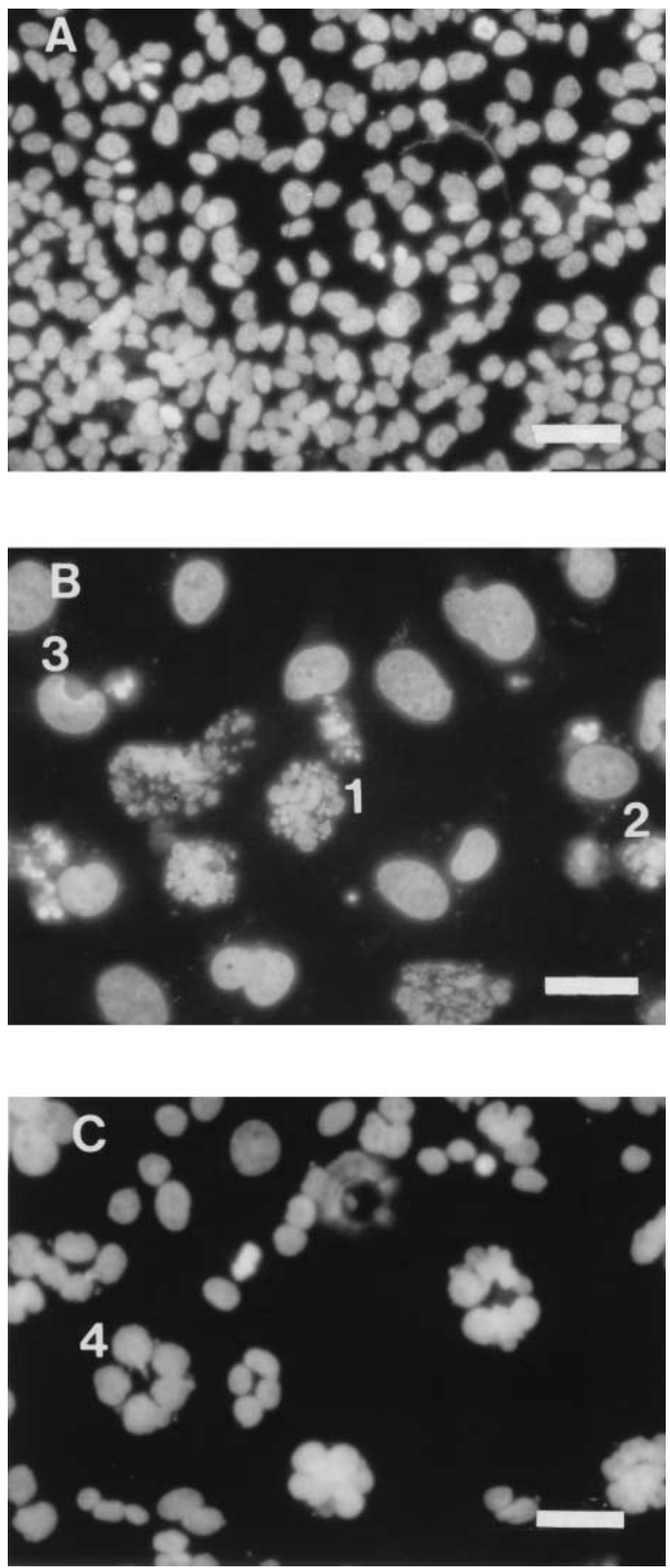

FIG. 4. Nuclear alterations displayed by HeLa cell monolayers on day 5 after a 4-h interaction (on day 1) with cultures of G2-8 (A) and BM2-1 (B) and with sterile sonicated extracts of BM2-1 interaction cultures (C). DAPI staining and a Zeiss $16 \times$ fluorescence objective lens were used. Bars $=20 \mu \mathrm{m} .1$, fragmented nucleus; 2 , apoptotic nucleus; 3 , bean-shaped nucleus; 4 , multinucleation.

intensely condensed masses of chromatin near the nuclear membrane, a lesion that is reminiscent of apoptosis, and (iii) bean-shaped nuclei enclosing a sharply circumscribed zone with reduced stainability. With a bacterial inoculum of $10^{8}$ $\mathrm{CFU} / \mathrm{ml}$, these specific alterations were estimated to affect about 35,20 , and $5 \%$ of total cells, respectively, at day 7 . In addition, signs of mitosis (chromosome condensation and for- mation of metaphase plaque) were not detectable. In comparison, multinucleated cells resulting from exposure to sonicated extracts of interaction cultures displayed no such lesions at day 5 (Fig. 4C).

To further investigate the nature of DNA lesions associated with the nuclear alterations observed in the CPE, we used the in situ TUNEL technique, which detects 3'-hydroxyl ends of DNA fragments. As depicted in Fig. 5, two of the nuclear alterations described above were labelled by this assay, namely lesions 2 and 3 . This observation would confirm the apoptotic nature of lesion 2. As regards lesion 3, the labelling concerned only the circumscribed area with reduced DAPI stainability.

Analysis of DNA content by flow cytometry. The arrest in cell proliferation with concomitant enlargement of nuclear size suggested that even though mitosis was inhibited after interaction with strain BM2-1, DNA synthesis still occurred. To test this hypothesis, we studied the time course of alteration of DNA content in cells exposed for $4 \mathrm{~h}$ to $10^{8} \mathrm{CFU}$ of strain BM2-1 or control strain G2-8 per ml, using flow cytometry methods. DNA content of cells exposed to sonicated cell extracts of strain BM2-1 was also monitored in an attempt to define more specifically their differences from cells exposed to bacteria (Fig. 6). Whereas cells exposed to control strain G2-8 behaved like normal cells during the whole period of observation (Fig. 6A), cells exposed to strain BM2-1 displayed a particular pattern of DNA content (Fig. 6B). The number of cells
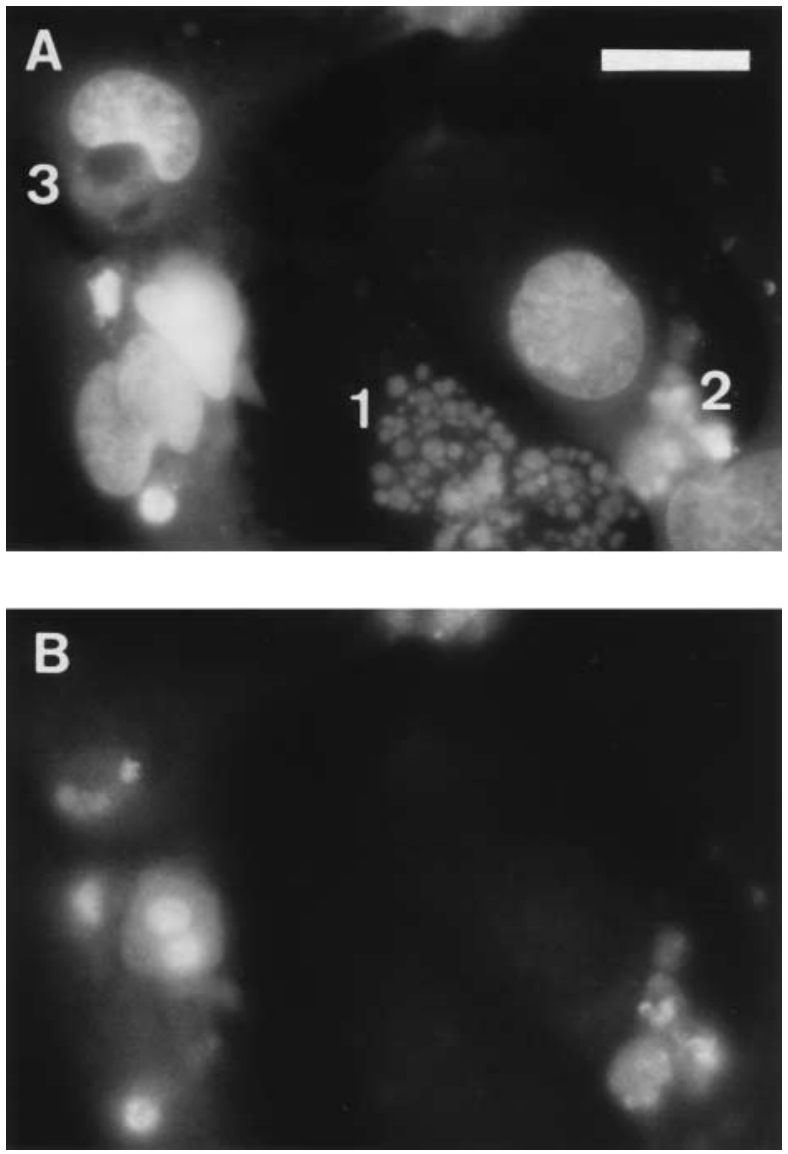

FIG. 5. Double-staining technique using DAPI for total chromatin staining and TdT fluorescein in situ labelling for visualization of 3 '-hydroxyl DNA strand breaks in nuclei. (A) DAPI filter; (B) fluorescein filter. A Zeiss $40 \times$ fluorescence objective lens was used. Bar $=20 \mu \mathrm{m}$. 1, fragmented nucleus; 2, apoptotic nucleus; 3 , bean-shaped nucleus. 
A
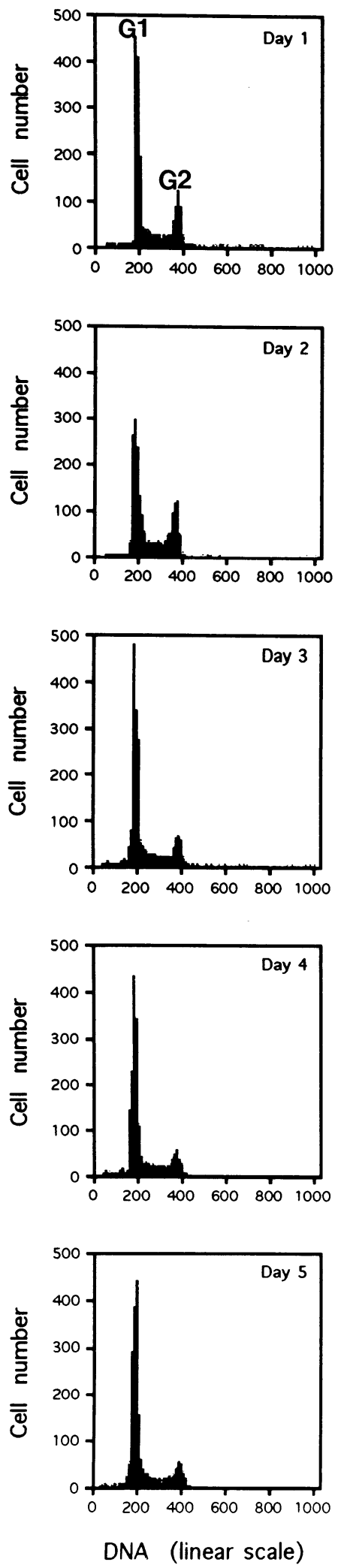

B
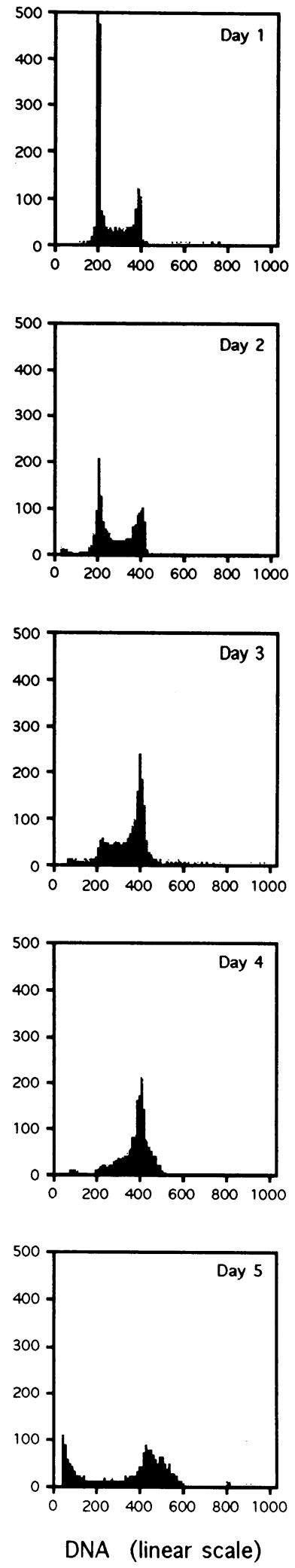

C
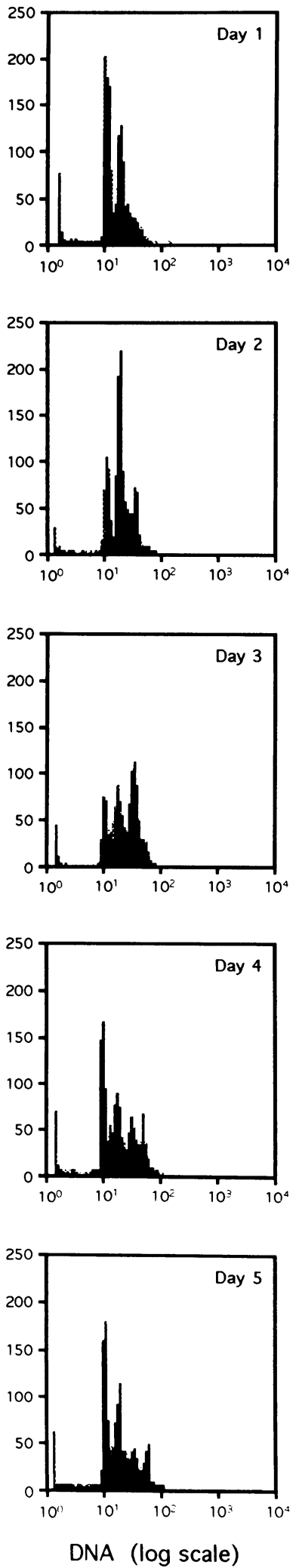

FIG. 6. Flow cytometry monitoring of HeLa DNA content after interaction with CNF1-producing strain BM2-1 (B), mutant strain G2-8 lacking CNF1 activity (A), and crude sonicated extract of BM2-1 (C). (A and B) Established HeLa cells in $75-\mathrm{cm}^{2}$ tissue culture flasks $\left(2 \cdot 10^{6}\right.$ cells per flask) were infected for $4 \mathrm{~h}$ on day 1 with strain BM2-1 or strain G2-8 (inoculum of about $10^{8} \mathrm{CFU} / \mathrm{ml}$ ) in MEM. Next, they were washed thoroughly to eliminate bacteria and incubated for specified periods of time in MEM containing gentamicin, as described in Materials and Methods. (C) Sonicated extract of strain BM2-1 was prepared from a 4-h bacterial culture in MEM, strictly under the same conditions as used for the experiments whose results are shown in panels A and B, sterilized by filtration (filter pore size, $0.2 \mu \mathrm{m}$ ), and then placed on established HeLa cell monolayers for $4 \mathrm{~h}$, after which it was replaced by normal MEM. At specified times, cells were trypsinized, fixed, permeabilized, and stained with propidium iodide for flow cytometry analysis. Note that the DNA scale for panel C is logarithmic instead of linear. 


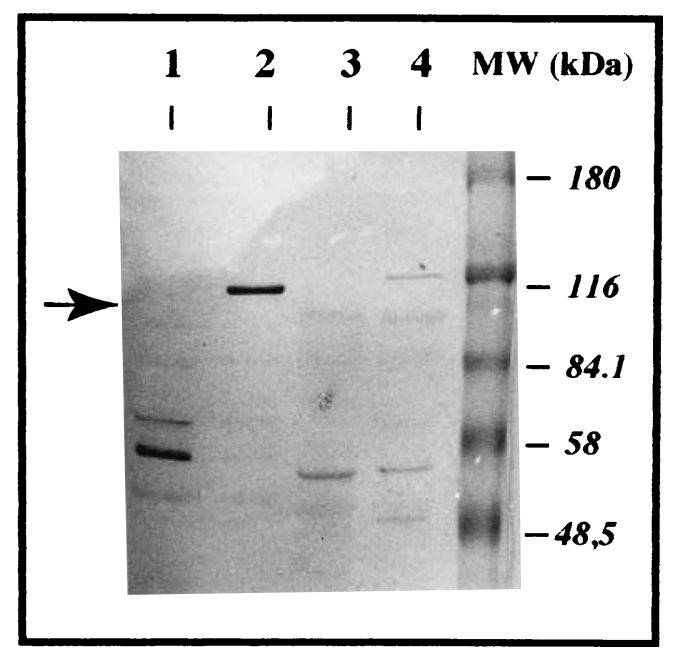

FIG. 7. Sodium dodecyl sulfate-polyacrylamide gel electrophoresis (SDSPAGE) immunoblotting of bacterial lysates showing the absence of the $115-\mathrm{kDa}$ CNF1 protein in Tn5::phoA mutant strain G2-8. Lane 1, control negative strain HB101; lane 2, control positive strain HB101(pISS 392); lane 3, mutant negative strain G2-8; lane 4, parental positive strain BM2-1. Briefly, sonicated extracts were enriched in CNF1 activity by a simplified chromatographic procedure using $50 \%$ ammonium sulfate precipitation, DEAE-Trisacryl ion-exchange chromatography, and ultrafiltration, as previously described (10). They were then run in SDS-7.5\% PAGE gels by using $100 \mu \mathrm{g}$ of protein per lane for strains BM2-1 and G2-8 and $10 \mu \mathrm{g}$ for strains HB101 and HB101(pISS385). After transfer onto nitrocellulose membrane, proteins were demonstrated by an immunoperoxidase technique using a 1/400 dilution of a rabbit CNF1-neutralizing antiserum produced as described previously (10). The arrow shows the $115-\mathrm{kDa}$ CNF1 protein, which is lacking in the profile of mutant strain G2-8. MW, molecular mass.

in $G_{1}$ gradually declined, while the number of those in $G_{2}$ increased up to day 4 , at which time practically all cells were blocked in $\mathrm{G}_{2}$. At day 5 , the $\mathrm{G}_{2}$ peak flattened and a sub- $\mathrm{G}_{1}$ peak, indicative of cellular lysis, appeared. In contrast, cells initially exposed for $4 \mathrm{~h}$ to sonicated cell extracts of the same interaction cultures were not arrested in $G_{2}$. Their DNA content could increase up to fourfold, which was illustrated by the occurrence of four equidistant peaks, shown in the log-scale diagram at day 4 (Fig. 6C). This phenomenon was correlated with the presence of cells with 1, 2, 3, or even more nuclei (Fig. 2A). By day 5, peaks corresponding to multinucleated cells regressed, coinciding with the reappearance of normal cells in the population (Fig. 2B). These results, which were highly reproducible, show that cells exposed to cytolethal doses of strain BM2-1 were totally blocked at stage $\mathrm{G}_{2}$ of the cell cycle. By contrast, cells exposed to free CNF1 extracts from the same cultures were allowed to replicate their DNA at least four times, although cytokinesis was blocked.

Lack of freely diffusible cytotoxic activity in culture supernatants. We examined whether CPE could result from the release of a toxic activity in the medium during the assay. To this end, we tested the cytotoxicity of sterile supernatants of 4-h interaction cultures, produced as described in Materials and Methods. When applied for $4 \mathrm{~h}$ on new HeLa cell monolayers, supernatants induced no detectable cytotoxic effect. The same held true when incubation was prolonged up to $8 \mathrm{~h}$. This observation showed that cytotoxicity was not caused by a factor freely diffusible in the medium during interaction. Secondly, we attempted to prevent $\mathrm{CPE}$ with a rabbit anti-CNF1 antibody, known to neutralize CNF1 effect at a high titer (11). Added to a 1:40 final dilution during the test of interaction and the subsequent incubation period, the immune serum had no detectable neutralizing activity. In contrast, the same serum did neutralize the activity of sonicated cell extracts of the same interaction cultures at a 1:5,620 dilution.

Absence of hemolysin contribution to the CPE. As reported above, CNF-defective Tnpho $A$ mutant G2-8 produced hemolysin at a titer similar to that of parental strain BM2-1 but did not induce any detectable CPE in HeLa cells, even at large doses (Fig. 1 and 3). Besides, we have further experimental evidence demonstrating that hemolysin does not participate in the induction of CPE. Firstly, the library of BM2-1 TnphoA mutants was also screened for loss of hemolysin activity, which is readily detectable on blood agar. We have selected four mutants. All of them have lost their immediate cytolytic effect on HeLa cells but retain the CNF1 production and CPE activity of the parental strain. Secondly, spontaneous hemolysinnegative mutants of BM2-1 were also selected on blood agar, at a rate of about $10^{-3}$. All these hemolysin-negative mutants retain $\mathrm{CNF} 1$ production and the ability to produce a $\mathrm{CPE}$ on HeLa cells.

Contribution of CNF1 structural gene (cnf-1) to the CPE. As shown above, Tn5::pho $A$ mutant strain G2-8, which lacked CNF1 production, was not pathogenic in the assay of interaction. To ascertain the precise contribution of $c n f-1$ to the CPE, strain G2-8 was therefore thoroughly analyzed according to immunochemical and genetical criteria. Firstly, we confirmed that the lack of CNF1 activity on HeLa cells was associated with the specific loss of the CNF1 115-kDa immunoreactive band in Western blotting analysis, using a rabbit antiserum neutralizing CNF1 toxicity (Fig. 7). Secondly, genomic DNA preparations of both G2-8 and BM2-1 were analyzed by Southern blotting. Results obtained with the TnphoA probe showed that a single transposon was inserted in the chromosome of the mutant strain. Disruption of $c n f-1$ by TnphoA insertion was suggested by the results obtained by Southern blot analysis with the CNF1 probe. According to these results, the transposon was most likely inserted in the $3^{\prime}$ end of cnf- 1 (data not shown). This conclusion was further confirmed by PCR analysis using boiling preparations of BM2-1 or G2-8 as the DNA template (Fig. 8). Briefly, a 1,114-bp fragment was amplified from the DNA of G2-8 and BM2-1 with primers CNF1-U1843 and CNF1-L2934. A 1,227-bp fragment was amplified from the DNA of BM2-1 with primers CNF1-U1843 and CNF1-L3044. A 1,207-bp fragment was amplified from the DNA of G2-8 with primers CNF1-U1843 and TnPhoA-L54. By contrast, no product was amplified from the DNA of G2-8 with primers CNF1-U1843 and CNF1-L3044 and from the DNA of BM2-1 with primers CNF1-U1843 and TnPhoA-L54. Taken together, these results allowed us to estimate the location of the TnphoA insertion between nucleotide 2934 and nucleotide 3044 of cnf-1. It is recalled that the structural gene of CNF1 is an open reading frame of 3,045 nucleotides (15).

Because Tn5 insertion frequently causes polar effects on downstream genes of an operon, proper insertion of the transposon in $c n f-1$ did not prove that this gene itself was involved in the production of the $\mathrm{CPE}$. We have consequently examined if CPE could be restored in G2-8 after complementation in trans with an exogenous recombinant plasmid containing $c n f-1$. For this purpose, DNA of pISS392 was digested with the restriction enzymes $A c c$ I and EcoRI, yielding a $3.5-\mathrm{kb}$ DNA fragment which contains cnf-1 and its own promoter. This DNA fragment was subcloned in pILL570-NotI cut with ClaI and EcoRI. The clones that acquired the recombinant plasmid, called pEOSW80, also acquired the ability to produce CNF1. After mating of SM10 $\lambda$ pir(pEOSW80) with recipient strains BM2-1 and G2-8, transconjugants were selected on M9 minimal agar supplemented with $1 \mu \mathrm{g}$ of thiamine per $\mathrm{ml}$ and $50 \mu \mathrm{g}$ of spectinomycin per $\mathrm{ml}$. Similar mating experiments were 


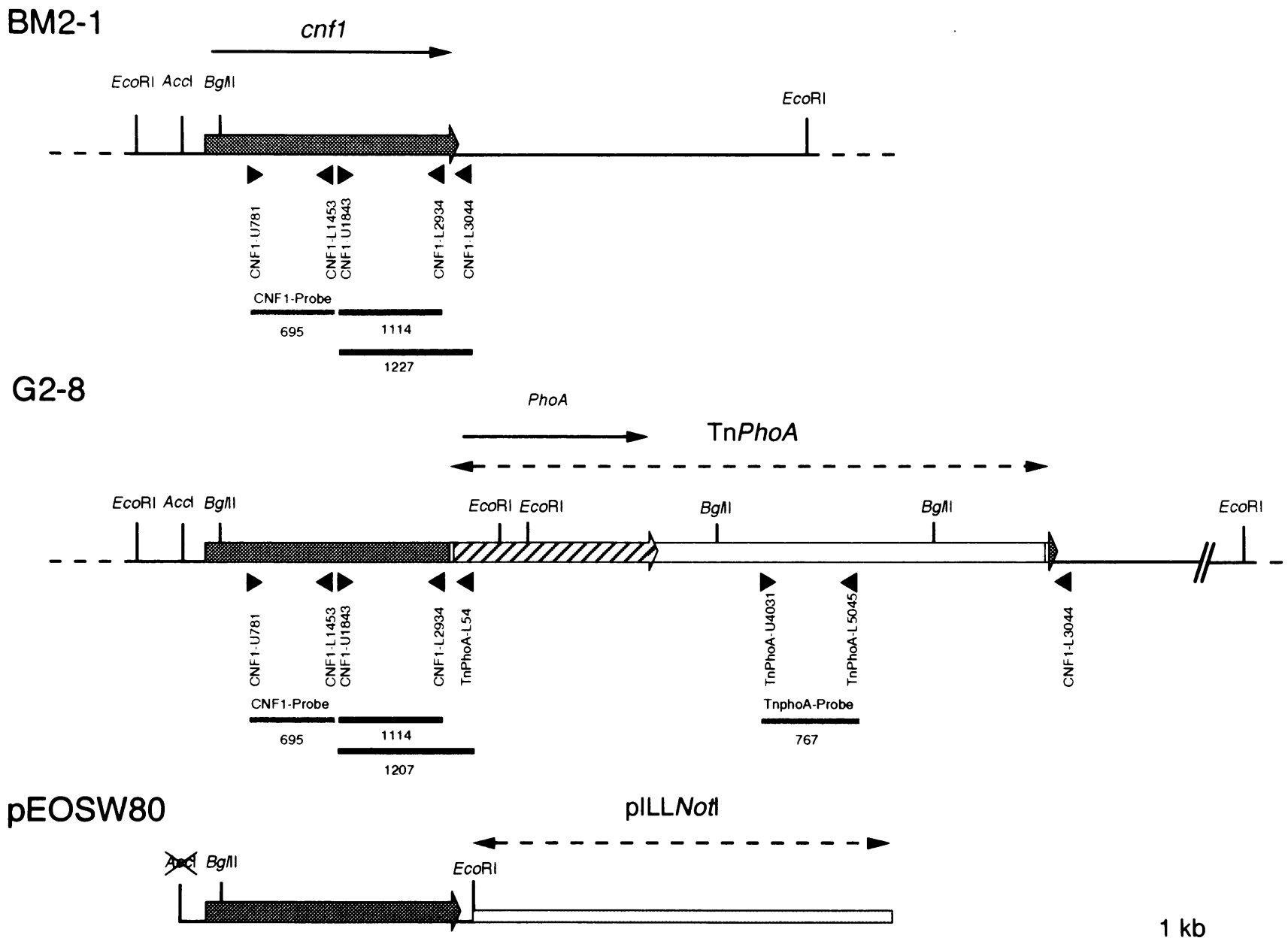

FIG. 8. Schematic of E. coli BM2-1 and G2-8 DNA analysis

performed with SM10 $\lambda$ pir(pILL570-NotI). The cytopathogenic effects of BM2-1(pILL570-NotI), BM2-1(pEOSW80), G2-8(pILL570-NotI), and G2-8(pEOSW80) were compared. As expected, the acquisition of pEOSW 80 by G2-8 restored the production of CNF1 in sonicated extracts to a level that was about four times higher than in the parental strain. However, this complementation did not restore the ability to produce a detectable CPE following interaction with HeLa cells (Fig. 9). By comparison, the introduction of pEOSW80 in the parental strain BM2-1 led to a four- to eightfold increase of CNF1 activity in sonicated extracts, in comparison with the level for both BM2-1 and BM2-1(pILL570-NotI). This increase in CNF1 production was correlated with a significant increase in CPE activity of the same order of magnitude, as shown by the dose-response comparative study (Fig. 9). It is worth noting that the introduction of the above-mentioned plasmids led to a significant reduction of bacterial growth in the interaction medium. This observation accounts for the smaller cytolethal effect at day 7 observed with BM2-1(pILL570-NotI) in comparison with BM2-1 (Fig. 3B). This also explains why, in Fig. 9, we have chosen to express cytolethality at day 7 as a function of bacterial biomass at the end of the interaction period.

The above result supported a determinant role for $c n f-1$ in the production of the CPE. However, the absence of production of a CPE by complemented G2-8 suggested that one or several essential genes, possibly downstream of $c n f-1$, were affected by the insertion.

Contribution of type 1 and F1C fimbriae to the CPE. The lack of cytotoxicity in culture supernatants of interaction cultures strongly suggested that a close contact between bacteria and HeLa cells was required to transfer the cytotoxic activity. As reported above, a massive but loose binding was observed during the interaction period, with both the wildtype strain and the CNF1-deficient mutant. We examined the contributions of established fimbriae present on strain BM2-1, namely type 1 and $\mathrm{F} 1 \mathrm{C}$, to the induction of $\mathrm{CPE}$ and the loose-adhesion phenotype. For this purpose, we checked whether specific inhibitors of type 1 and F1C fimbriae were able to significantly decrease cytotoxic activity when added to the medium during the test of interaction. These inhibitors were mannose, for type 1 fimbriae (concentration, 1\%), and F1C antiserum (concentration, 1/50). Tests were performed according to a dose-response protocol, by using 24 wellculture plates and four wells per experimental point. On day 7 , total protein content of cell monolayers was quantified by methylene blue incorporation, as described in Materials and Methods. Whatever the bacterial inoculum used, no significant inhibition of CPE could be observed with either mannose or F1C antiserum ( $t$ test, $P>0.05$ ). Concomitantly, we performed similar inhibition tests with Lab-Tek chamber slides, in order 


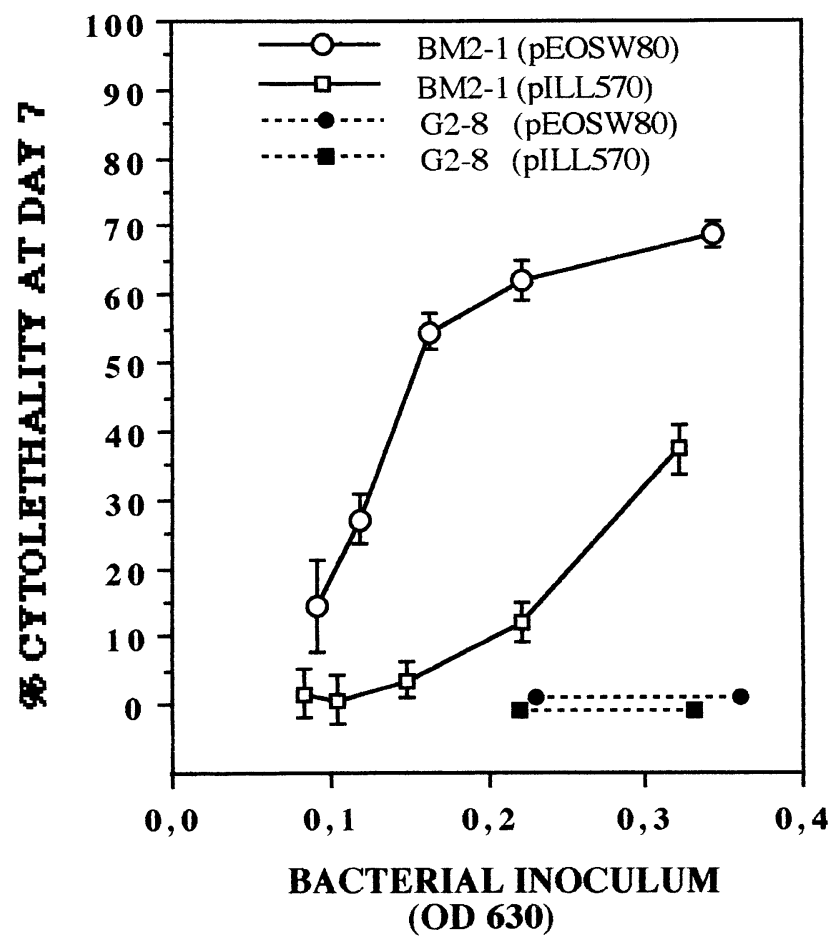

FIG. 9. Cytolethal effects produced in HeLa cell monolayers by strains G2-8 and BM2-1 carrying plasmid pILL570-NotI (control) or plasmid pEOSW80 (cloned cnf-1). Tests of interaction were carried out over a 4-h period according to a dose-response protocol (four wells per experimental point). To account for any difference in bacterial growth during the assay, inoculum size was assessed as the mean optical density at $630 \mathrm{~nm}$ (OD 630) of interaction cultures, at the end of the assay. Percent cytolethality was measured at day 7 by determination of total protein content of cell monolayers by using methylene blue staining, with reference to nonexposed control cells (four wells per experimental point; error bars represent standard errors).

to detect a possible decrease in adhesion at the end of the interaction period. None of these potential inhibitors was able to noticeably decrease the adhesion displayed by strain BM2-1. These experiments showed that neither of the two established fimbrial adhesins present in strain BM2-1, namely type 1 and F1C, seemed to contribute significantly to the CPE and the loose-adhesion phenotype.

\section{DISCUSSION}

The overall objective of this study was to examine if a temporary infection of HeLa cell cultures with CNF1-producing $E$. coli BM2-1 was able to trigger a pathogenic effect that could be ascribed to CNF1. The relevance of this question was linked to the fact that CNF are cell-associated toxins that are not significantly released in culture medium $(6,11)$. Our findings show that an interaction of short duration between bacterial organisms and HeLa cells does induce a dose-related specific CPE in HeLa cells and that this CPE is linked to CNF1 but seemingly not caused by the release of a freely diffusible form of CNF1 in the culture medium.

The features of the CPE allow us to define an original pattern of pathogenicity, which may be relevant to the observed clinical association of CNF-producing E. coli with infection of epithelia. The CPE can be summarily described as a delayed cytolethal effect that follows profound alterations of both the cytoskeleton and the nucleus. Functionally, it is characterized by an irreversible arrest of cell proliferation in the $G_{2}$ phase of the cell cycle. To further define the specificity of the $\mathrm{CPE}$, we compared it with the effect produced in HeLa cells by sonicated cell extracts of interaction cultures, which contain free CNF1. Although both effects are characterized by the formation of giant cells streaked with actin stress fibers, they differ essentially by the way in which mitosis is affected, as shown by cell cycle analysis by flow cytometry (Fig. 6). Exposure of cells to CNF1 bacteria totally prevents entry into mitosis, whereas exposure to free CNF1 allows all stages of mitosis, except cytokinesis, to occur. This basic difference in cell cycle modification explains the absence of multinucleation in cells exposed to bacteria, an absence that was observed over the whole range of inocula tested.

Delayed cell lethality is also a highly relevant feature of the CPE. In our model, cytolethality occurred from day 5 after interaction, concomitantly with the appearance of nuclear lesions. This lethality followed a phase of about 4 days during which cells, although their proliferation was stopped, were probably still able to synthesize proteins, as shown by the significant enlargement of cells and of their nuclei and the measurement of total protein content (Fig. 3). The delayed nature of the cytolethal activity suggests the existence of a second messenger system: bacteria deliver the lethal information during their short effective interaction with cells, and following this initial interaction, cells mount a sequence of biochemical events leading irreversibly to death. This mechanism of delayed cytolethality differs essentially from the rapid lethal effect that has been described for cultured epithelial cells following infection with enteropathogenic (2) or hemolytic (8) E. coli. In the present study, the immediate lethal effect of hemolysin was totally prevented by the addition of neutralizing antibodies. The contribution of hemolysin to the CPE was ruled out by the fact that the nonpathogenic G2-8 mutant retained full hemolytic activity. The lack of participation of hemolysin in the CPE was further corroborated by our observation that spontaneous and $\operatorname{Tn} p h o A$ hemolysin-negative mutants of the parental strain retain both $\mathrm{CNF}$ production and cytopathic activity.

The mechanism of cell death was investigated through the study of nuclear lesions. We were able, using DAPI staining, to repeatedly observe three types of nuclear morphological alterations, one of which was reminiscent of apoptosis, as shown by the intense condensation of chromatin near the nuclear membrane and the formation of apoptotic bodies (Fig. 4). The apoptotic nature of the latter alteration was confirmed by in situ labelling by the TUNEL technique, which detects $3^{\prime}$-hydroxyl ends of DNA strand breaks. Unexpectedly, another type of alteration, namely circumscribed zones of reduced DAPI stainability enclosed in bean-shaped nuclei, was also labelled by using this technique (Fig. 5). Notwithstanding, the most frequent alteration consisted in a complete disintegration of nuclei. The latter alteration was not labelled by the TUNEL technique and cannot therefore be qualified as apoptosis. The relative complexity of this picture may be related to the heterogeneity of cells with regard to their position in the cell cycle at the time of interaction. This hypothesis could be tested by using synchronized HeLa cell cultures. Such a strategy could lead to homogeneous preparations of cells with each of the three types of nuclear alterations observed.

A mechanism of apoptosis toward a macrophage cell line has been recently demonstrated with Shigella flexneri (41) and Bordetella pertussis (20). In both cases cell death associated with characteristic DNA fragmentation occurred within 4 to 6 $\mathrm{h}$ following interaction with pathogenic bacteria, a phenomenon which is essentially different from the delayed cell death that we have observed in the present study. The specific effect 
of CNF-producing E. coli on the cell cycle of exposed cells seems to us more reminiscent of the activity of various DNAdamaging agents, such as ionizing radiation or camptothecin, that induce a blockade in $\mathrm{G}_{2} / \mathrm{M}$ phases of the cell cycle followed by the induction of apoptosis $(24,36)$.

As regards the general mechanism of interaction between bacteria and cells, our observations indicate that CPE does not result from the release of a freely diffusible form of CNF1 into the cell culture medium. This assertion is based on two independent experimental observations. Firstly, we were not able to induce a CPE by exposing cells to freshly prepared cell-free supernatants of $E$. coli BM2-1 interaction cultures, even when incubation was prolonged over $4 \mathrm{~h}$. Secondly, the CPE was not significantly prevented by addition of anti-CNF1 antibodies that otherwise neutralized free CNF1 at a high titer. The first of these observations shows that no significant toxic activity is liberated in the medium during the interaction. The second one suggests that the active form of CNF1 in the assay of interaction no longer possesses the neutralizing epitopes that are present on the native CNF1 protein or, more likely, that the toxin is not exposed to the external medium during its translocation into the host cell.

If the cytopathic activity is not triggered by the release of a freely diffusible form of toxic activity into the culture medium, then we should admit the existence of a direct mechanism of interaction between bacteria and HeLa cells. In the present study, we have limited our analysis to the role of established adhesins present on strain BM2-1, i.e., type 1 and F1C fimbrial adhesins. Specific inhibition of these adhesins did not significantly decrease pathogenicity, which seems to rule out any specific contribution of these adhesins in our model. This result could largely be expected, since the standardized experimental conditions did not specifically favor the expression of either of these fimbriae (33) and since HeLa cells do not express specific receptors for F1C (23). The role of the socalled loose-adhesion phenotype that was demonstrated in the present study should now be investigated in detail. This adhesion was described as loose because, in contrast to the situation with binding mediated by most fimbrial adhesins, bacteria could be removed by repeated washings. However, when fixation was performed before the washings, then binding appeared to be both massive and specific for cells. To our knowledge, the loose-adhesion phenotype has never explicitly been described before for $E$. coli, but it has been reported to occur in the initial phase of Salmonella adhesion to epithelial cell surfaces (17).

We also postulated that some degree of bacterial internalization could have contributed to the induction of the CPE. This occurrence was considered in the present study, because CNF1 has previously been shown to trigger phagocytosis in cultured epithelial cells (16). However, our experiments suggest that bacterial internalization was not significant at the end of the interaction period, as shown by Giemsa staining of washed cell monolayers and by counting of viable bacteria that had escaped the bactericidal activity of gentamicin 3 and $24 \mathrm{~h}$, respectively, after interaction. These observations would indicate that CPE is not dependent upon bacterial invasion during the interaction period or dependent upon the persistence (and multiplication) of bacteria after the interaction period itself. This, however, does not preclude the possibility of delayed acquisition of phagocytosis ability by epithelial cells exposed to CNF-producing E. coli. Falzano et al. (16) indeed observed that ability to internalize bacteria (or inert particles) was acquired by cultured epithelial cells only after $12 \mathrm{~h}$ of exposure to free CNF1. This hypothesis could be tested in the HeLa cell model of infection described here by rechallenging monolayers $24 \mathrm{~h}$ after the initial interaction.

One of our chief objectives was to assess the exact contribution of CNF1 to the CPE produced by strain BM2-1. Our argumentation is based both on morphological considerations and on genetic experiments. Firstly, the production of actin stress fibers across the entire cell can be considered highly specific for CNF1 since, to our knowledge, it has not been described to date for cells exposed to other bacterial toxins or pathogens (13). Secondly, we were able to completely abolish the CPE through transposon mutagenesis of strain BM2-1 in the CNF1 structural gene (cnf-1). The resulting mutant strain, G2-8, was devoid of significant pathogenicity over the whole range of inocula tested (Fig. 3). Aside from providing us with an adequate control strain, this result strongly suggested that CNF1 itself participates in the induction of CPE. However, because of the known polar effect of Tn 5 insertion, the loss of pathogenicity in strain G2-8 could also be attributable to the inhibition of a gene downstream of $c n f-1$. This happened to be the case, as demonstrated by trans complementation of strain G2-8 with recombinant plasmid pEOSW80, which contains cnf-1. Although the level of CNF1 production was significantly higher in the complemented strain than in the parental strain, the CPE could not be restored. This determinant observation shows that at least one gene, possibly downstream of $c n f-1$, is necessary to produce the CPE. The role of $c n f-1$ itself is supported by the correlative enhancement of both CNF1 activity and CPE ability in the parental strain BM2-1 after its acquisition of recombinant plasmid pEOSW80 (Fig. 9). The existence of several genes acting concurrently with $c n f-1$ to determine pathogenicity toward HeLa cells is thus most likely. These would include, in particular, genes responsible for the binding of bacteria to cells, those contributing to the secretion of CNF1, and those triggering the transfer of the toxic activity into target cells. Such a multifactorial process has been described to occur with, for instance, the YopE cytotoxin of Yersinia spp. (29).

To our knowledge, induction of a mitosis block leading to delayed cell death has never been described so far as a potential mode of pathogenicity for bacterial organisms. Together with the induction of specific cytoskeletal alterations, these pathogenic properties could account for the involvement of CNF-producing $E$. coli in infection of epithelia, for instance, through impediment of cell renewal or the alteration of such essential properties as cell polarity and barrier functions. Provided that the original pathogenic properties described here can be extrapolated to other clinical isolates of CNF-producing E. coli, our work opens three complementary fields of research: (i) the identification of bacterial genes acting together with cnf- 1 to promote cytopathogenicity, (ii) the elucidation of the mechanisms through which bacteria deliver the toxic instructions to host cells, and (iii) the unravelling of the second messenger program in host cells that results in mitosis block and delayed lethality.

\section{ACKNOWLEDGMENTS}

This work was funded by grants from INRA (Action Incitative Programmée no. 4/4997) and from the Conseil Régional de la Région Midi-Pyrénées (no. 9308102).

We are grateful to P. Boquet and M. R. Popoff (Pasteur Institute) for fruitful discussion during the course of this study. We are also indebted to J. Mainil (Veterinary Faculty of Liège), M. Dho-Moulin (INRA), and C. Le Bouguenec (Pasteur Institute) for their help in the characterization of the E. coli strain and to V. Falbo for the gift of plasmid pISS392. We also express our gratitude to A. Milon for his constant support. 


\section{REFERENCES}

1. Alonso, M., J. Blanco, M. Blanco, and E. A. Gonzales. 1987. Frequent production of toxins by Escherichia coli isolated from urinary tract infections: relation with haemagglutination. FEMS Microbiol. Lett. 48:391-396.

2. Baldwin, T. J., M. B. Lee-Delaunay, S. Knutton, and P. H. Williams. 1993. Calcium-caldmodulin dependence of actin accretion and lethality in cultured Hep-2 cells infected with enteropathogenic Escherichia coli. Infect. Immun. 61:760-763.

3. Bhakdi, S., N. Mackman, J. M. Nicaud, and I. B. Holland. 1986. Escherichia coli hemolysin may damage target cell membranes by generating transmembrane pores. Infect. Immun. 52:63-69.

4. Blanco, J., E. A. Gonzáles, S. Garcia, M. Blanco, B. Regueiro, and I. Bernárdez. 1988. Production of toxins by Escherichia coli strains isolated from calves with diarrhea in Galicia (northwestern Spain). Vet. Microbiol. 18:297311.

5. Caprioli, A., G. Donelli, V. Falbo, R. Possenti, L. G. Roda, G. Roscetti, and F. M. Ruggeri. 1984. A cell-division-active protein from Escherichia coli. Biochem. Biophys. Res. Commun. 118:587-593.

6. Caprioli, A., V. Falbo, L. G. Roda, F. M. Ruggeri, and C. Zona. 1983. Partial purification and characterization of an Escherichia coli toxic factor that induces morphological cell alterations. Infect. Immun. 39:1300-1306.

7. Caprioli, A., V. Falbo, F. M. Ruggeri, L. Baldassari, R. Bisicchia, G. Ippolito, E. Romoli, and G. Donelli. 1987. Cytotoxic necrotizing factor production by hemolytic strains of Escherichia coli causing extraintestinal infections. J. Clin. Microbiol. 25:146-149.

8. Colonna, B., L. Ranucci, P. A. Fradiani, M. Casalino, A. Calconi, and M. Nicoletti. 1992. Organization of aerobactin, hemolysin, and antibacterial resistance genes in lactose-negative Escherichia coli strains of serotype O4 isolated from children with diarrhea. Infect. Immun. 60:5224-5231.

9. De Rycke, J., E. A. Gonzales, J. Blanco, E. Oswald, M. Blanco, and R. Boivin. 1990. Evidence of two types of cytotoxic necrotizing factor (CNF1 and CNF2) in human and animal clinical isolates of Escherichia coli. J. Clin. Microbiol. 28:694-699.

10. De Rycke, J., J. F. Guillot, and R. Boivin. 1987. Cytotoxins in nonenteropathogenic strains of Escherichia coli isolated from feces of diarrheic calves. Vet. Microbiol. 15:137-150.

11. De Rycke, J., L. Phan Than, and S. Bernard. 1989. Immunochemical identification and biological characterization of cytotoxic necrotizing factor of Escherichia coli. J. Clin. Microbiol. 27:983-988.

12. De Rycke, J., and G. Plassiart. 1990. Toxic effects for lambs of cytotoxic necrotising factor (CNF) from Escherichia coli. Res. Vet. Sci. 49:349-354.

13. Donelli, G., and C. Fiorentini. 1994. Bacterial toxins acting on the cell cytoskeleton. Microbiologica 17:345-362.

14. Elsinghorst, E. A. 1994. Measurement of invasion by gentamicin resistance. Methods Enzymol. 236:405-420.

15. Falbo, V., T. Pace, L. Picci, E. Pizzi, and A. Caprioli. 1993. Isolation and nucleotide sequence of the gene encoding cytotoxic necrotizing factor 1 of Escherichia coli. Infect. Immun. 61:4909-4914.

16. Falzano, L., C. Fiorentini, G. Donelli, E. Michel, C. Kocks, P. Cossart, L. Cabanié, E. Oswald, and P. Boquet. 1993. Induction of phagocytic behaviour in human epithelial cells by Escherichia coli cytotoxic necrotizing factor type 1. Mol. Microbiol. 9:1247-1254.

17. Finlay, B. B., F. Heffron, and S. Falkow. 1989. Epithelial cell surfaces induce Salmonella proteins required for bacterial adhesion and invasion. Science 243:940-943.

18. Fiorentini, C., G. Arancia, A. Caprioli, V. Falbo, F. M. Ruggeri, and G. Donelli. 1988. Cytoskeletal changes induced in Hep-2 cells by the cytotoxic necrotizing factor of Escherichia coli. Toxicon 26:1047-1056.

19. Gorczyca, W., J. Gong, B. Ardelt, F. Traganos, and Z. Darzynkiewicz. 1993. The cell cycle related differences in susceptibility of HL-60 cells to apoptosis induced by various antitumor drugs. Cancer Res. 53:3186-3192.

20. Khelef, N., A. Zychlinsky, and N. Guiso. 1993. Bordetella pertussis induces apoptosis in macrophages: role of adenylate cyclase hemolysin. Infect. Immun. 61:4064-4071.
21. Knutton, S., T. Baldwin, P. H. Williams, and A. S. McNeish. 1989. Actin accumulation at sites of bacterial adhesion to tissue cultures: basis of a new diagnostic test for enteropathogenic and enterohemorrhagic Escherichia coli. Infect. Immun. 57:1290-1298.

22. Labigne, A., V. Cussac, and P. Courcoux. 1991. Shuttle cloning and nucleotide sequences of Helicobacter pylori genes responsible for urease activity. J. Bacteriol. 173:1920-1931.

23. Marre, R., B. Kreft, and J. Hacker. 1990. Genetically engineered S and F1C fimbriae differ in their contribution to adherence of Escherichia coli to cultured renal tubular cells. Infect. Immun. 58:3434-3437.

24. Muschel, R. J., H. B. Zhang, G. Iliakis, and W. G. McKenna. 1991. Cyclin B expression in HeLa cells during the $\mathrm{G} 2$ block induced by ionizing radiation. Cancer Res. 51:5113-5117.

25. Oswald, E. 1995. Unpublished data.

26. Oswald, E., and J. De Rycke. 1990. A single protein of 110kDa is associated with the multinucleating and necrotizing activity coded by the Vir plasmid of Escherichia coli. FEMS Microbiol. Lett. 68:279-284.

27. Oswald, E., J. De Rycke, J. F. Guillot, and R. Boivin. 1989. Cytotoxic effect of multinucleation in HeLa cell cultures associated with the presence of Vir plasmid in Escherichia coli strains. FEMS Microbiol. Lett. 58:983-988.

28. Oswald, E., M. Sugai, A. Labigne, H. C. Wu, C. Fiorentini, P. Boquet, and A. D. O'Brien. 1994. Cytotoxic necrotizing factor type 2 produced by virulent Escherichia coli modifies the small GTP-binding proteins rho involved in assembly of actin stress fibers. Proc. Natl. Acad. Sci. USA 91:3814-3818.

29. Rosqvist, R., K. E. Magnusson, and H. Wolf-Watz. 1994. Target cell contact triggers expression and polarized transfer of Yersinia yopE cytotoxin into mammalian cells. EMBO J. 13:964-972.

30. Ruggeri, F. M., C. Fiorentini, A. Caprioli, G. Arancia, V. Falbo, and G. Donelli. 1986. Hep-2 cells multinucleation induced by an Escherichia coli cytotoxic factor. IRCS Med. Sci. 14:833-834.

31. Sambrook, J., E. F. Fritsch, and T. Maniatis. 1989. Molecular cloning: a laboratory manual, 2nd ed. Cold Spring Harbor Laboratory Press, Cold Spring Harbor, N.Y

32. Smith, H. W. 1975. Observations on Escherichia coli infections in calves, p. 47-59. In J. M. Rutter (ed.), Proceedings of the First Seminar on "Pathology" in the CEC Programme of Coordination of Research in Beef Production. Commission of the European Communities, Brussels.

33. Smyth, C. J., M. Marron, and S. G. J. Smith. 1994. Fimbriae of Escherichia coli, p. 399-435. In C. L. Gyles (ed.), Escherichia coli in domestic animals and humans. CAB International, Wallingford, United Kingdom.

34. Tabouret, M., and J. De Rycke. 1990. Detection of cytotoxic necrotising factor (CNF) in extracts of Escherichia coli strains by enzyme-linked immunosorbent assay. J. Med. Microbiol. 32:73-81.

35. Taylor, R. K., C. Manoil, and J. J. Mekalanos. 1989. Broad-host-range vectors for delivery of TnphoA: use in genetic analysis of secreted virulence determinants of Vibrio cholerae. J. Bacteriol. 171:1870-1878.

36. Tsao, Y. P., P. D'Arpa, and L. F. Liu. 1992. The involvement of active DNA synthesis in camptothecin-induced G2 arrest: altered regulation of p34 ${ }^{\mathrm{cdc} 2}$ cyclin B. Cancer Res. 52:1823-1829.

37. Van die, I., B. Van Geffen, W. Hoekstra, and H. Bergmans. 1985. Type F1C fimbriae of an uropathogenic Escherichia coli strain: cloning and characterization of the genes involved in the expression of the $1 \mathrm{C}$ antigen and nucleotide sequence of the subunit gene. Gene 34:187-196.

38. Welch, R. A., and S. Falkow. 1984. Characterization of Escherichia coli hemolysins conferring quantitative differences in virulence. Infect. Immun. 43:156-160

39. Wilson, A. P. 1992. Cytotoxicity and cell viability assays, p. 263-303. In R. I Frishney (ed.), Animal cell culture, a practical approach. IRL Press, Oxford.

40. Wray, C., D. W. T. Piercy, P. J. Carroll, and W. A. Cooley. 1993. Experimental infection of neonatal pigs with CNF toxin-producing strains of Escherichia coli. Res. Vet. Sci. 54:290-298.

41. Zychlinsky, A., M. C. Prevost, and P. J. Sansonetti. 1992. Shigella flexner induces apoptosis in infected macrophages. Nature (London) 358:167-168.

Editor: B. I. Eisenstein 